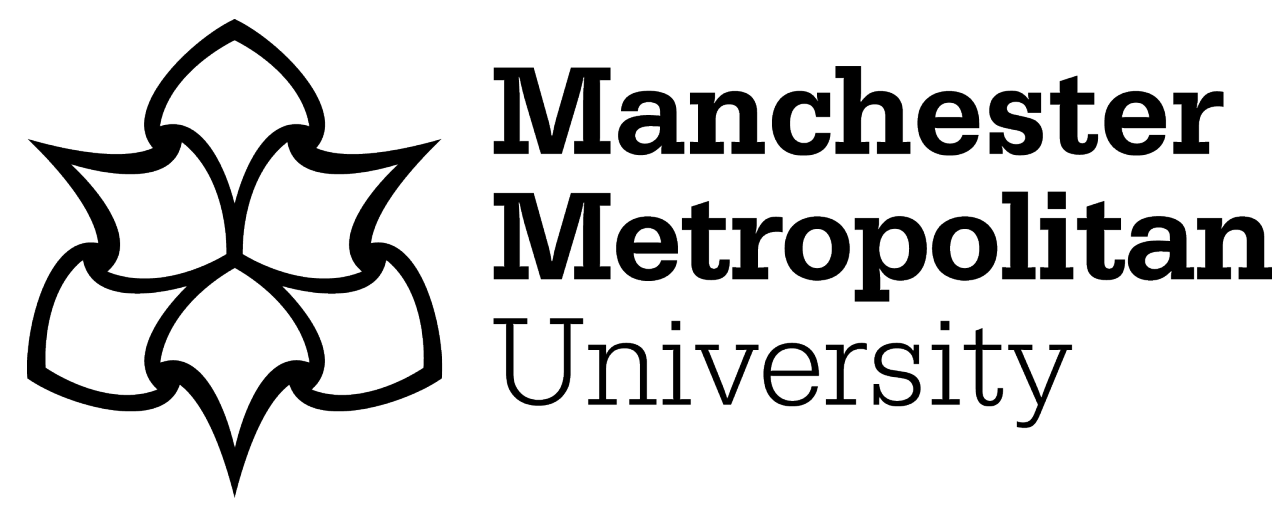

Stacy, J, Yost, AJ, Regmi, YN ORCID logoORCID: https://orcid.org/00000001-6588-7683, Leonard, B, Chien, TY and Fan, M (2017) A Facile Synthesis of Highly Stable Modified Carbon Nanotubes as Efficient Oxygen Reduction Reaction Catalysts. ChemistrySelect, 2 (5). pp. 1932-1938. ISSN 2365-6549

Downloaded from: https://e-space.mmu.ac.uk/624777/

Version: Accepted Version

Publisher: Wiley

DOI: https://doi.org/10.1002/slct.201600810

Please cite the published version 


\title{
A Facile Synthesis of Highly Stable Modified Carbon Nanotubes as Efficient Oxygen Reduction Reaction Catalysts
}

John Stacy ${ }^{\mathrm{a}}$, Andrew John Yost $^{\mathrm{b}}$, Yagya N Regmi ${ }^{\mathrm{c}}$, Brian Leonard ${ }^{\mathrm{c}}$, TeYu Chien ${ }^{\mathrm{b}}$, Maohong $\operatorname{Fan}^{\mathrm{a}, \mathrm{d}}$

${ }^{a}$ Department of Chemical and Petroleum Engineering, University of Wyoming, Laramie, Wyoming, 82071, USA

${ }^{b}$ Department of Physics and Astronomy, University of Wyoming, Laramie, Wyoming, 82071, USA

${ }^{c}$ Department of Chemistry, University of Wyoming, Laramie, Wyoming, 82071, USA

${ }^{d}$ School of Energy Resources, University of Wyoming, Laramie, Wyoming, 82071, USA

* Corresponding author: Maohong Fan; mfan@uwyo.edu

Keywords: Carbon, Electrochemistry, Fuel Cell, Heterogeneous Catalysis, Metal-Free Catalysts

\begin{abstract}
Proton Exchange Membrane Fuel Cell (PEMFC) technology is an exciting alternative energy prospect, especially in the field of transportation. PEMFCs are three times as efficient as internal combustion (IC) engines and emit only water as a byproduct. The latter point is especially important in a day and age when climate change is upon us. However, platinum required to catalyze the sluggish oxygen reduction reaction (ORR) which takes place on the cathode of the PEMFC has rendered fuel cell automobiles economically unviable. Therefore, the
\end{abstract}


pursuit of an inexpensive replacement for platinum has become an active research area. Herein, a facile synthetic process for modified carbon nanotubes for ORR catalysis is described. X-ray photoemission spectroscopy (XPS) and Raman spectroscopy confirm the inclusion of surface carbonyl groups in these modified nanotubes. Via rotating disk electrode (RDE) experiments in an alkaline medium, the modified nanotubes were found to equal the activity of a Pt/C standard and exceed the stability of the platinum catalyst. Density functional theory (DFT) and scanning tunneling microscopy (STM) studies serve to provide theoretical and experimental electronic property information which explain the improved ORR activity seen by the modified nanotubes. 


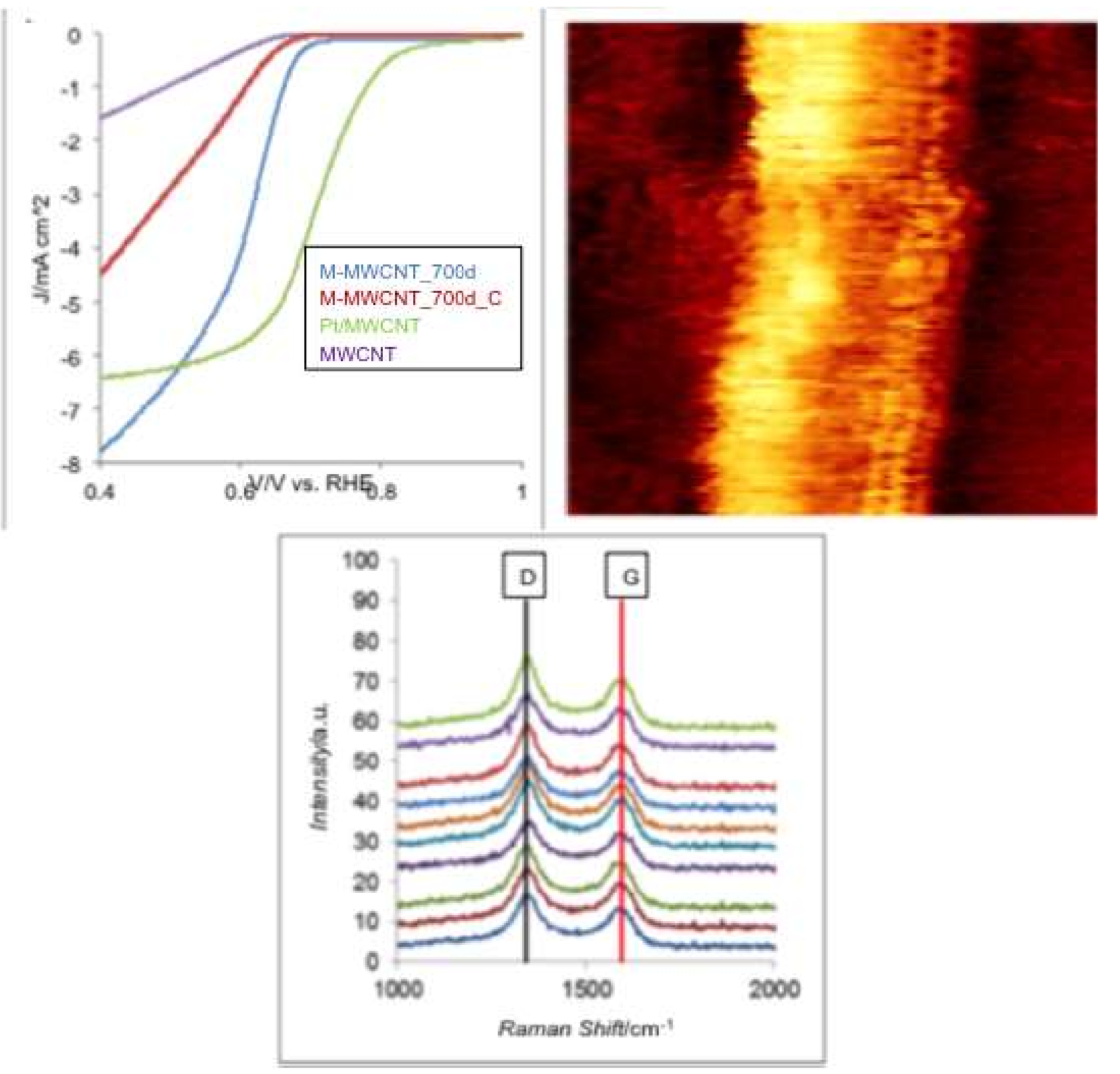

\section{Table of Contents}

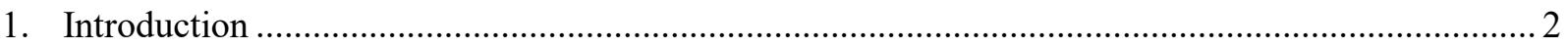

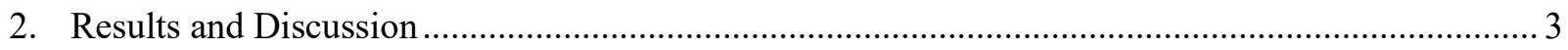

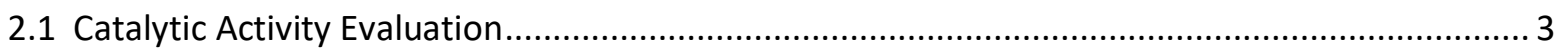

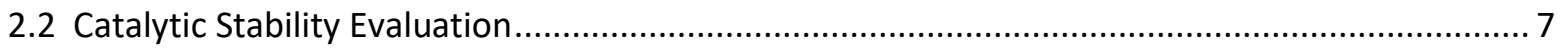

2.3 Scanning Tunneling Microscopy and Spectroscopy (STM/S) ............................................... 8

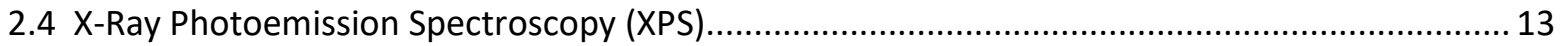

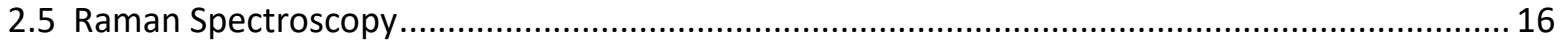

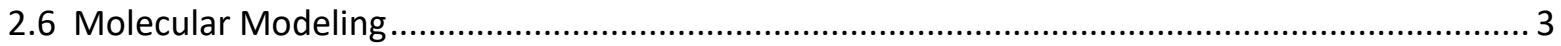




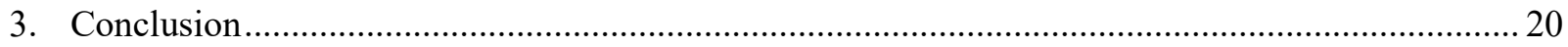

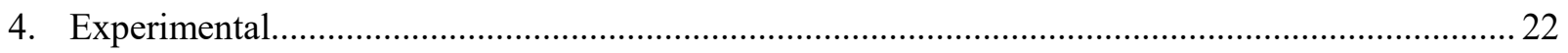

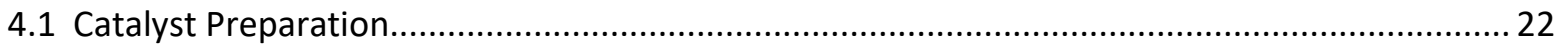

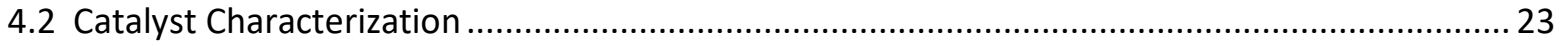

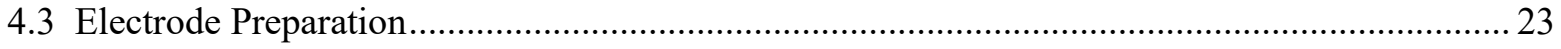

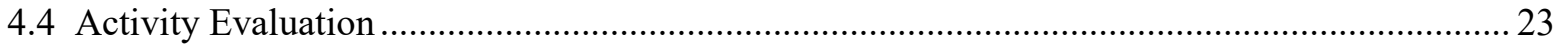

\section{INTRODUCTION}

Oxygen reduction reaction (ORR) catalysis research is a burgeoning field due to its application in proton exchange membrane fuel cells (PEMFCs). The current state of the art for ORR catalysis in PEMFCs is carbon supported platinum nanoparticles. ${ }^{[1]}$ These materials are efficient catalysts, but they drive the cost of PEMFCs up to the point where they are not economically viable for commercial use. ${ }^{[2,3]}$ Therefore, search for inexpensive materials as efficient or more efficient in catalyzing ORR is an important and potentially barrier breaking field. Efforts to reduce or eliminate the need for platinum or other precious metals have already been made. Alloying platinum with less expensive transition metals has improved upon ORR activity while decreasing the necessary platinum. However, these catalysts still require platinum and therefore remain expensive. ${ }^{[4,5]}$ Precious metal free catalysts such as $\mathrm{Co}_{3} \mathrm{O}_{4}$ nanocrystals and $\mathrm{MnCo}_{2} \mathrm{O}_{4}$ nanoparticles have shown activity rivaling that of $\mathrm{Pt} / \mathrm{C}$, but they have trouble standing up to the harsh environment of PEMFCs. ${ }^{[6,7]}$ Carbon based, metal-free materials with efficient ORR activity are the ideal materials for the PEMFC industry.

Recently, modified multiwalled carbon nanotubes (MWCNT's) have shown drastic improvement in ORR efficiency compared to untreated MWCNT's in $1 \mathrm{M} \mathrm{KOH}$. These MWCNT's were chemically modified resulting in the addition of carboxyl, hydroxyl and 
nitrophenyl groups to the surface. ${ }^{[8]}$ Herein, a method of modifying MWCNTs is described which introduces defects and carbonyl groups to the surface, giving rise to highly stable and efficient ORR catalysts.

\section{RESULTS AND DISCUSSION}

\subsection{CATALYTIC ACTIVITY EVALUATION}

Samples prepared including an eight hour dwell time are herein described with a suffix of "d" following the maximum temperature reached. For example, the sample treated at $500{ }^{\circ} \mathrm{C}$ with an eight hour dwell time is denoted as M-MWCNT_500d. Control samples, prepared under a nitrogen atmosphere, will be referred to with the suffix "C."

A clear optimization of temperature was identified among the M-MWCNT_200d through M-MWCNT_1000d samples, displayed in Figure 1(a). Activity trended upwards as temperature increased until a sharp maximum was seen in the M-MWCNT_700d sample. 

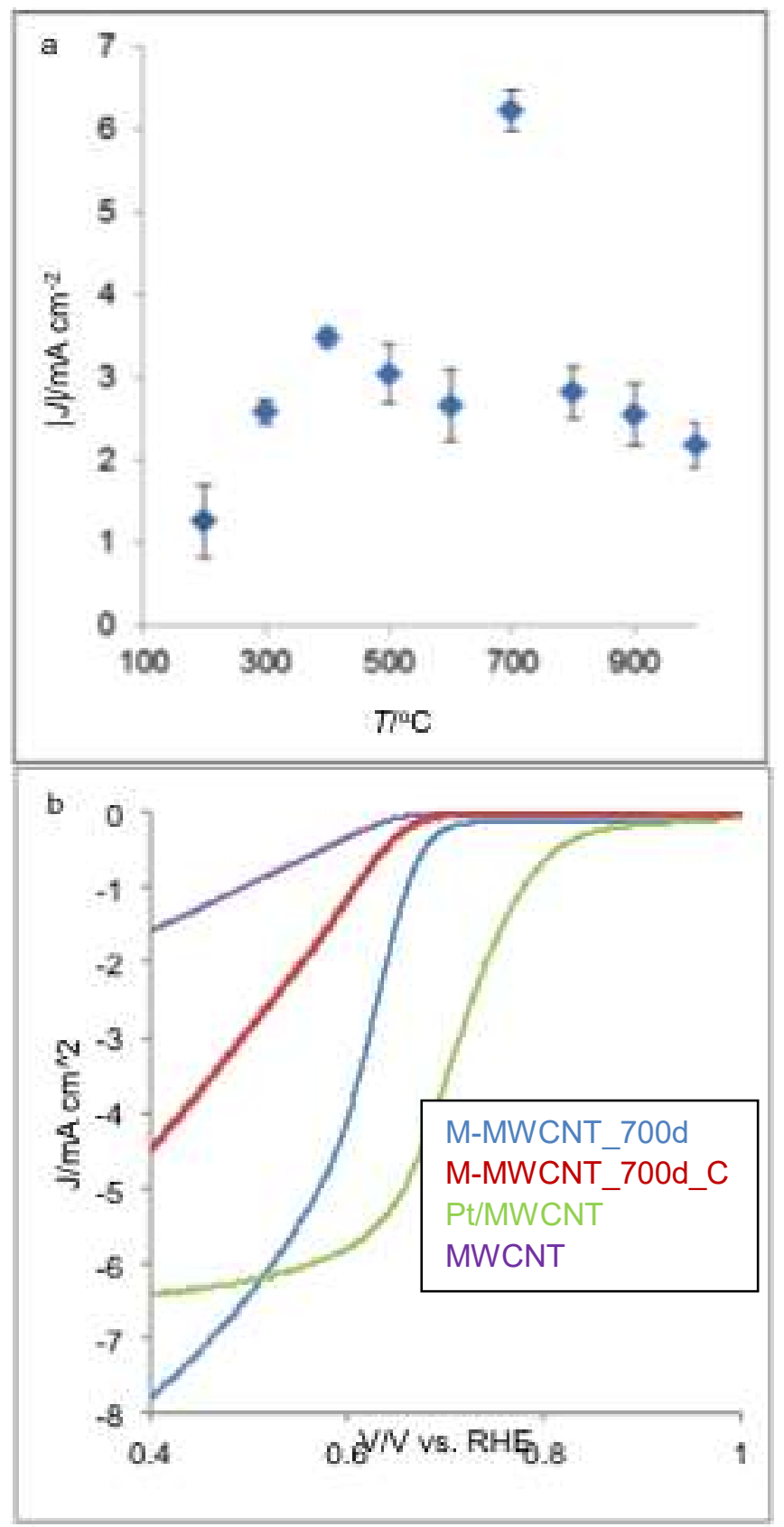

Figure 1. (a) A plot showing the absolute value of the current density measured at $0.5 \mathrm{~V}$ vs. RHE for M-MWCNT_200d through M-MWCNT_1000d. Tests carried out in 0.1 M KOH solution with a disk speed of 1600 RPM. (b) LSV curves of untreated MWCNTs, Pt/MWCNT standard, M-MWCNT_700d and M-MWCNT_700d_C 
Once the optimized samples were identified, catalytic testing was done on untreated MWCNTs to set a base line as well as on a $6 \% \mathrm{Pt} / \mathrm{MWCNT}$ catalyst to compare the samples to a Pt standard. These results are displayed in Figure 1(b). Not surprisingly, the M-MWCNT-700d sample out-performed untreated MWCNTs in terms of both onset potential and current density at $0.5 \mathrm{~V}$ vs. RHE. The Pt/MWCNT sample did out-perform the M-MWCNT-700d sample in terms of onset potential. The Pt/MWCNT sample displayed an onset potential of $0.835 \mathrm{~V}$ vs. RHE compared to 0.698 V vs. RHE shown by the M-MWCNT_700d samples At 0.5 V vs. RHE (an acceptable operating voltage for PEMFC's ${ }^{[9]}$ ), the M-MWCNT_700d sample showed a current density equaling that of the Pt standard. At 0.5 V vs. RHE, both the M-MWCNT_700d sample and the Pt/MWCNT standard exhibited an average current density of $-6.23 \mathrm{~mA} \mathrm{~cm}{ }^{-2}$.

To determine the role of ammonia treatment in the improved ORR activity of MMWCNT_700d, control experiments were run in which MWCNTs were dwelled at $700^{\circ} \mathrm{C}$ for eight hours under a nitrogen atmosphere. As is seen in Figure 1(b), the sample heated under an $\mathrm{N}_{2}$ atmosphere had a less positive onset potential and a lower current density at $0.5 \mathrm{~V}$ vs. RHE. This shows that the presence of ammonia, not just the thermal treatment, is essential to induce the improved ORR activity seen by M-MWCNT_700d.

\subsection{CATALYTIC STABILITY EVALUATION}

To test the stability of the catalysts, they were subjected to 500 consecutive cyclic voltammetry (CV) cycles between 1.064 and -0.436 V vs. RHE. During these stability tests, current density measurements at $0.5 \mathrm{~V}$ vs. RHE were taken via LSV after every 100 cycles. Tests were performed on a Pt/MWCNT standard as well as a M-MWCNT_700d sample, and the results are shown in Figure 2. The modified nanotube sample proved to stand up much more 
robustly to the harsh fuel cell environment than the Pt/MWCNT standard. The Pt/MWCNT standard showed a $44.6 \%$ decline in current density compared to a19.9 \% loss shown by MMWCNT_700d. So, not only does the M-MWCNT sample compare favorably to the Pt/MWCNT standard in initial ORR activity, but its ability to maintain a high activity after stability tests also makes it an attractive alternative to Pt for ORR catalysis.

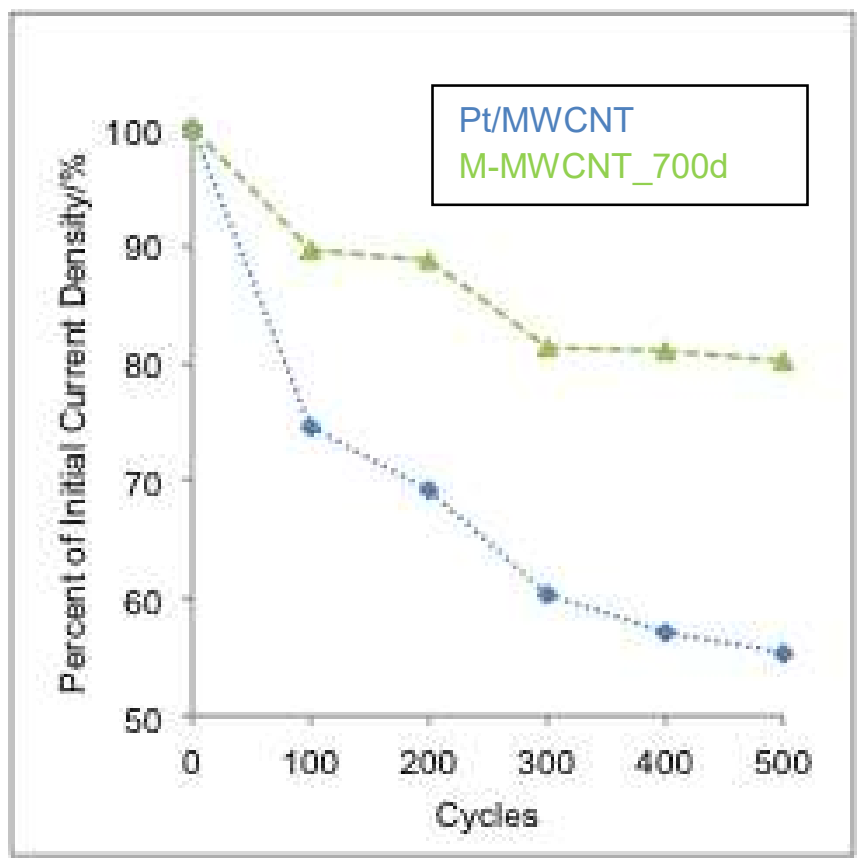

Figure 2. Stability testing showing the percent of initial current density at $0.5 \mathrm{~V}$ vs. RHE exhibited after 100, 200, 300, 400 and 500 cycles between 1.064 and $-0.436 \mathrm{~V}$ vs. RHE

\subsection{Scanning Tunneling Microscopy and Spectroscopy (STM/S)}

Scanning tunneling microscopy and spectroscopy (STM/S) was used to obtain the topography as well as electronic local density of states (LDOS) of the treated and untreated MWCNTs. STM employs the quantum tunneling effects for electrons to tunnel through vacuum gap from a metallic tip to a conductive or semiconducting sample or vice versa. ${ }^{[10]}$ A technique commonly known as scanning tunneling spectroscopy (STS) is used to measure the differential 
conductance $(d I / d V)$ between the tip-sample gap which is associated with the LDOS of the surfaces of the materials. The atomic resolution combined with the LDOS capability make STM/S the optimal tool for investigating the electronic effects of dopants and other chemical modifications on the MWCNTs and SWCNTs. ${ }^{[11-16]}$

The MWCNT samples for STM measurements were prepared by a drop-casting method, in which one droplet of a $0.5 \mathrm{mg} / \mathrm{mL}$ solution of untreated MWCNT or M-MWCNT powder in 2propanol was dropped onto a $1 \times 1 \mathrm{~cm}^{2}$ highly oriented pyrolytic graphite (HOPG) substrate. HOPG was chosen as the substrate because of its atomically flat surface and relatively stable scanning surface for STM measurements. ${ }^{[17]}$ The atomic structure of HOPG, as seen in Figure 3(a), indicates the STM tip is atomically sharp and capable of resolving carbon atoms. The lower portion of Figure 3(a) is an area of HOPG that is not entirely clean, likely dirty/rough area of clustered MWCNT nanotubes, showing that the surface is not pristine near or on the MWCNTs.

It is common that MWCNT and SWCNT tend to aggregate and form large clusters and clumps of many nanotubes when prepared by the drop-cast method. ${ }^{[12-16,18]}$ Bundled MWCNT structures are believed to be formed by van der Waals forces between the individual nanotubes. ${ }^{[18]}$ The tangled clusters present a challenge for STM topography as the roughness can be quite large. Atomic force microscopy (AFM) was utilized, see supporting information, to determine an appropriate concentration for drop-casting solutions of nanotubes in order to minimize clusters and maximize discrete nanotube deposition for STM measurements. As shown in Figure 3(b), untreated MWCNTs with a bundled structure were the most common structures of nanotube seen on the surface of HOPG with STM. Similar bundled structures of MWCNTs were reported by Odom et al. ${ }^{[14]}$ The width of this untreated MWCNT bundle structure is $\sim 20 \mathrm{~nm}$, and inside the 
bundle, it is easy to see the individual nanotubes have diameters in the range of $1.9-4.2 \mathrm{~nm}$. The M-MWCNT_700d sample also showed similar bundled structure, as shown in Figure 3(c). This bundled structure for the M-MWCNT_700d is determined have a width of $7.0 \mathrm{~nm}$. Inside the bundle of the M-MWCNT_700d, individual nanotubes measure approximately $0.6-2.0 \mathrm{~nm}$ in diameter.

In order to obtain electronic information for the MWCNTs, $d I / d V$ spectra were measured on isolated MWCNTs to prevent from picking up information due to interactions among MWCNTs in the same bundle. Figure 3(d) shows an isolated untreated MWCNT alongside a bundled structure, indicated by the arrows. This isolated nanotube has a diameter of $3.2 \mathrm{~nm}$. The STS spectra was measured and shown in Figure 4(b). It is known that SWCNTs can be either semiconducting or metallic depending on the diameter and the chirality, and MWCNTs are generally metallic. ${ }^{[11,13]}$ In the case of the untreated MWCNTs, the $d I / d V$ spectra indicates a metallic like structure which also contains well defined peaks around $0.5 \mathrm{~V}$ and at $-0.3 \mathrm{~V}$. In addition, there are two shoulder-like peaks located at around $0.2 \mathrm{~V}$ and another at around -0.89 V. The features in the MWCNT $d I / d V$ spectra shown in Figure 4(b) are consistent with reported spectrum for pristine carbon nanotubes. ${ }^{[1]}$

Unlike the untreated MWCNT, the treated MWCNT exhibits more peaks on the conduction band side (positive bias side), located at $0.13 \mathrm{~V}, 0.37 \mathrm{~V}, 0.56 \mathrm{~V}, 0.79 \mathrm{~V}, 1.10 \mathrm{~V}$, and $1.36 \mathrm{~V}$. It is interesting to note that the peaks seem to appear in pairs with each pair being separated by $\sim 0.24 \mathrm{~V}$. For the valence band side (negative bias side), there is only one extra peak located at -0.54 shown in the treated MWCNT compared to untreated MWCNT. A similar $d I / d V$ spectrum was reported by Czerw et al. on MWCNTs pyrolized with a ferrocene/melamine mixture in order to introduce nitrogen dopants. ${ }^{[15]}$ In combination with other theoretical studies 
$[16-18,20,21]$ and some models performed by Czerw et al. it was postulated that these paired peaks were the result of quasibound or electron donor states.

Comparison to the results put forth by Czerw et al. seems to indicate that there may be nitrogen doping occurring on the surface of the M-MWCNTs. However, Czerw et al. prove beyond doubt that there is pyridinic nitrogen present on the surface of the MWCNTs they produced ${ }^{[22]}$ whereas elemental analysis of M-MWCNT_700d shows no presence of nitrogen. Instead, carbonyl inclusion seems to be responsible for the improved ORR activity due to its presence in active samples and absence in the less active untreated samples. Carbonyl inclusion, according to molecular modeling seen in Figure 9, gives rise to a similar charge distribution in the surface carbons of SWCNTs to that seen in models of pyridinic nitrogen containing SWCNTs. Therefore, it is postulated that carbonyl inclusion is responsible for the large donor state at $0.13 \mathrm{~V}$ exhibited via STS which parallels that of the pattern seen in Czerw's N-doped nanotubes. These electronic similarities may also be responsible for the improved ORR of MMWCNTs, as N-doped carbon materials have proven to be efficient ORR catalysts in the past. [23] The presence of these additional peaks after the treatment process indicates a modification of the electronic properties of the nanotube surface. It can be postulated that the increased number of DOS represent an increased number of sites for catalyst $/ \mathrm{O}_{2}$ interaction. This would give rise to an increase in $\mathrm{O}_{2}$ adsorption, and therefore an improvement in ORR activity. 


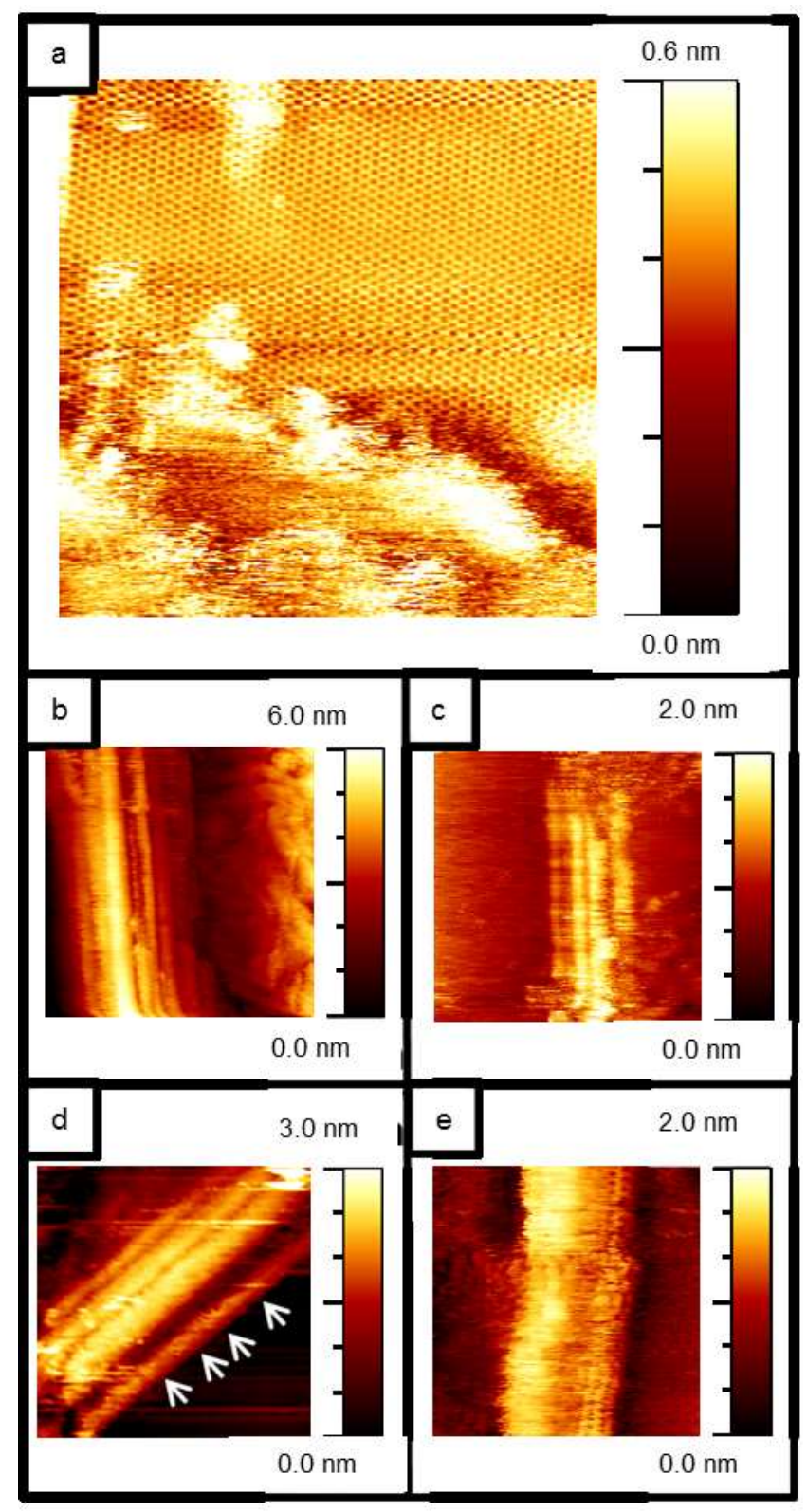

Figure 3. STM topography, Bias $=1.5 \mathrm{~V} \& \mathrm{I}_{\text {set }}=300 \mathrm{pA}$, image of (a) $10 \times 10 \mathrm{~nm}^{2}$ atomic resolution of HOPG (b) $43 \times 43 \mathrm{~nm}^{2}$ bundled nanotube structure of MWCNT (c) $21 \times 21 \mathrm{~nm}^{2}$ bundled nanotube structure of M-MWCNT_700d (d) $5 \times 5 \mathrm{~nm}^{2}$ discrete MWCNT alongside a MWCNT bundle (e) $5 \times 5 \mathrm{~nm}^{2}$ atomic resolution of M-MWCNT_700d 


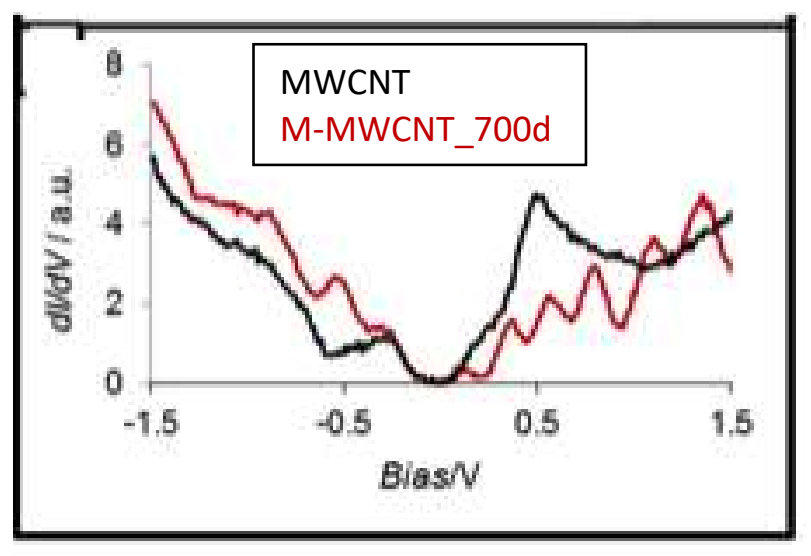

Figure 4. STS of MWCNT and M-MWCNT_700d, Bias $=1.5 \mathrm{~V} \& \mathrm{I}_{\mathrm{set}}=300 \mathrm{pA}$, bias ramped from 1.5 to $-1.5 \mathrm{~V}$

\subsection{X-ray Photoemission Spectroscopy (XPS)}

As shown in Figure 5, negligible differences were identified in the XPS survey scan between the ammonia treated samples and those treated under nitrogen. Each sample had a strong $\mathrm{C}$ 1s peak at $285 \mathrm{eV}$ with slight presence of oxygen identified by small peaks at $533 \mathrm{eV}$. As the samples were treated under a 10/90 ammonia/nitrogen atmosphere, one may have expected small amounts of nitrogen doping in the modified nanotubes. But, as is made evident by figures 12 and 13 in the supporting information, no nitrogen presence was identified via high resolution scans in the $\mathrm{N} 1 \mathrm{~s}$ region. However, upon examination of the high resolution $\mathrm{C}$ 1s scans of each sample, it becomes evident that the type of oxygen containing species vary between the ammonia treated sample and the control samples Deconvolution of the $\mathrm{C}$ 1s peak of the M-MWCNT_700d sample, available in supporting information, shows that it is made up mostly $\mathrm{sp}^{3}$ hybridized carbons, $284.75 \mathrm{eV}$, relating to the main graphitic structure of MWCNTs. [24] $41.2 \%$ of the $\mathrm{C} 1 \mathrm{~s}$ peak relates to these $\mathrm{sp}^{3}$ carbons. $12.7 \%$ corresponds to the $\pi-\pi$ interactions that occur between the walls of the nanotubes at $292 \mathrm{eV} .{ }^{[24]}$ The rest of the peaks are indicative of oxygen containing species. $20.2 \%$ corresponds to the $\mathrm{OH}$ peak at $285.5 \mathrm{eV}$, 
$13.0 \%$ corresponds to the carbonyl peak at 287.5 , and $12.9 \%$ corresponds to the $\mathrm{COOH}$ peak at 289.75. ${ }^{[24]}$ The striking difference between the sample treated with ammonia and the control sample is the absence of carbonyl content in the control material. M-MWCNT_700d_C shows $45.9 \% \mathrm{sp}^{3}, 15.1 \% \pi-\pi, 24.0 \% \mathrm{OH} 15.0 \%, \mathrm{COOH}$ and $0 \%$ carbonyl. The dramatic increase in activity between the control sample and that treated with ammonia leads to the conclusion that the presence of carbonyl groups on the surface of the nanotubes may be responsible for the improved ORR efficiency. FTIR analysis, available in supporting information, corroborates the presence of $\mathrm{C}=\mathrm{O}$ in treated samples and the absence of these groups in control samples. Indeed, Dumitru et al. have theorized that the presence of oxygen containing functional groups on the surface of MWCNTs may be credited for improved ORR activity. ${ }^{[8]}$

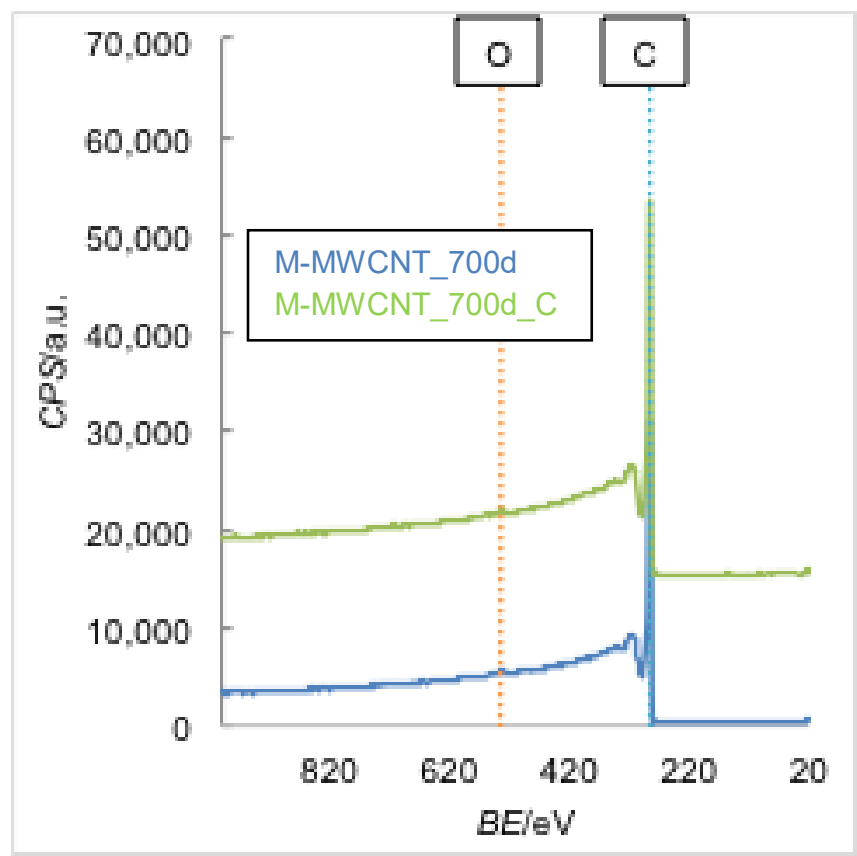

Figure 5. XPS comparing M-MWCNT_700d, M-MWCNT_800 and control samples treated under $\mathrm{N}_{2}$

Table 1. Table quantifying content of high resolution C 1s scans 


\begin{tabular}{|c|c|c|c|c|c|}
\hline \multicolumn{7}{|c|}{ C 1s Peak Deconvolution } \\
\hline Catalyst & $284.75(\mathrm{sp} 2 / \mathrm{sp} 3)$ & $285.5(\mathrm{OH})$ & $287.5(\mathrm{C}=\mathrm{O})$ & $289.75(\mathrm{COOH})$ & 292 (pi-pi) \\
\hline M-MWCNT_700d & 41.2 & 20.2 & 13 & 12.9 & 12.7 \\
\hline M-MWCNT_700d_C & 45.9 & 24 & 0 & 15 & 15.1 \\
\hline & & & & & \\
\hline
\end{tabular}

\subsection{RAMAN SPECTROSCOPY}

Raman spectroscopy was performed on a Snowy Range Instruments Raman Spectrometer with a green, $532 \mathrm{~nm}$ laser at a power level of $1 \mathrm{~mW}$. 50 scans were taken between 200 and $3200 \mathrm{~cm}^{-1}$ for each sample, and the average of these 50 scans is reported. A scan of the bare sample holder was taken after each run, and this baseline scan was subtracted from the acquired sample scan in order to normalize the runs. Two significant peaks were present in the Raman spectra. The peak at $1341 \mathrm{~cm}^{-1}$ represents disordered carbon (D) and the peak at $1601 \mathrm{~cm}^{-1}$ represents graphitic carbon $(G) .{ }^{[25]}$ A D/G ratio was obtained by finding the full width at half max of each D peak and dividing by the FWHM of the associated G peak.

All of the samples tested showed a higher $\mathrm{D} / \mathrm{G}$ ratio than untreated MWCNTs. For MMWCNT_200d through M-MWCNT_1000d a trend was recognized in the D/G ratio similar to the trend seen in the activity section above. $\mathrm{D} / \mathrm{G}$ increased until it reached a peak at $\mathrm{M}$ MWCNT_700d before decreasing again. The correlation between higher D/G ratios and higher ORR activity indicates that defects in the graphitic MWCNT surface give rise to higher ORR activity. XPS analysis indicates that the inclusion of $\mathrm{C}=\mathrm{O}$ groups on the surface of the 
MWCNTs is responsible for these defects. The control sample M-MWCNT_700d_C showed a higher $\mathrm{D} / \mathrm{G}$ ratio than untreated MWCNT's, but a lower $\mathrm{D} / \mathrm{G}$ than the corresponding sample that was treated under ammonia. This reaffirms the hypothesis that the presence of ammonia during the thermal treatment is necessary for the modification of the MWCNT's and subsequent improved activity.
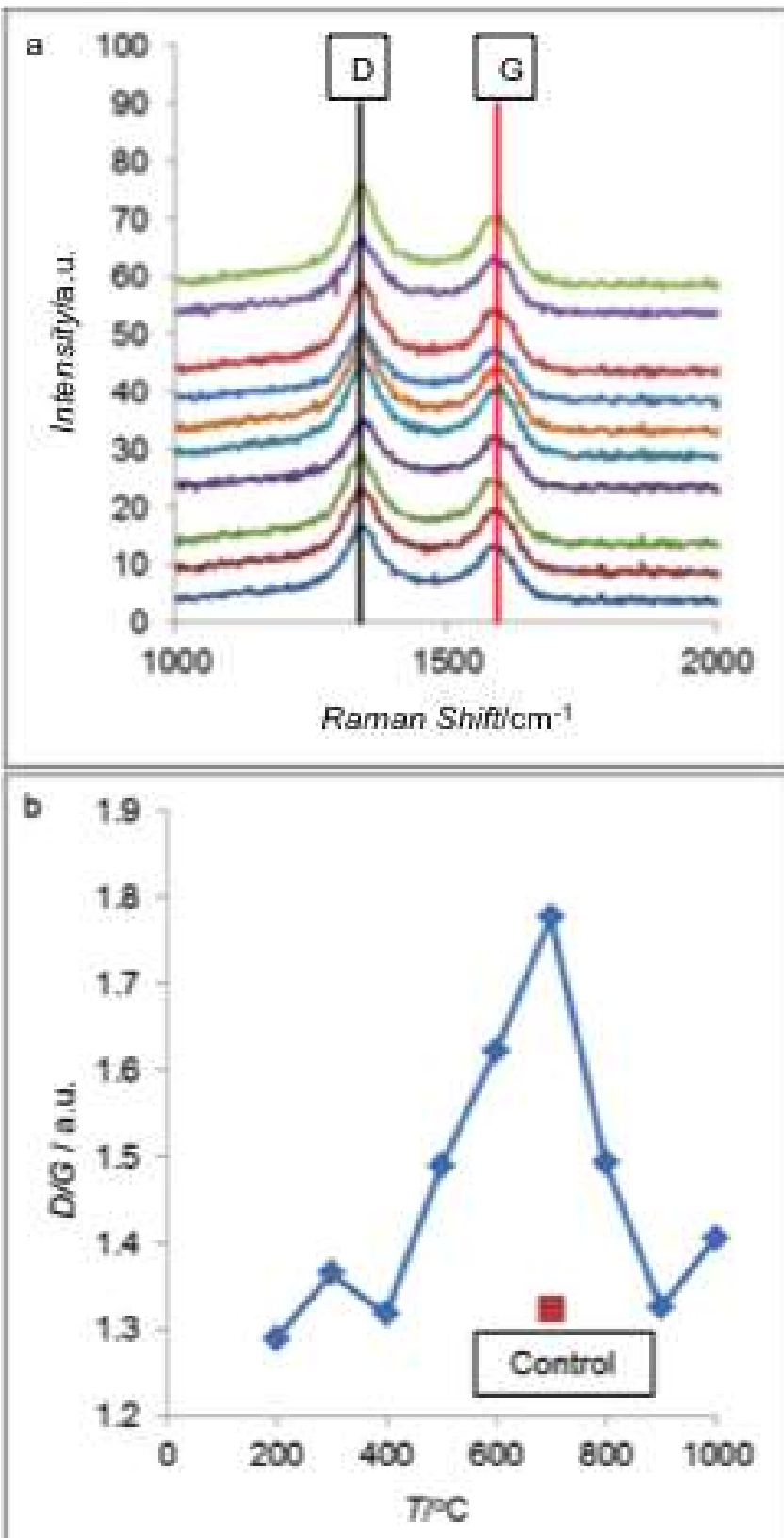
Figure 6. (a) Raman spectra in ascending order from M-MWCNT_200d through MMWCNT_1000d as well as for the control M-MWCNT_700d_C sample (fourth curve from the top). (b) D/G vs. temperature plot showing a peak at the most active M-MWCNT_700d sample.

\subsection{MOLECULAR MODELING}

Molecular models were generated for pristine SWCNTs and SWCNTs with defects associated with carbonyl groups. Charge density models gave rise to a possible explanation for the improved activity seen in the M-MWCNT's. The model of the $\mathrm{C}=\mathrm{O}$ containing tube shows a differential charge distribution with the carbon breaking the conjugation exhibiting a charge density of $\sim 2$ orders of magnitude higher than the carbons in the pristine CNTs and those adjacent showing charges $\sim 5$ times more positive. These partial positive charges, presumably, make for very attractive sites for oxygen adsorption, initiating ORR. Figure 9(c) is a molecular model of a SWCNT doped with pyridinic nitrogen as that described by Czerw et al. ${ }^{[15]}$ This tube shows similar electronic characteristics in both STS studies as well as the charge density model. 


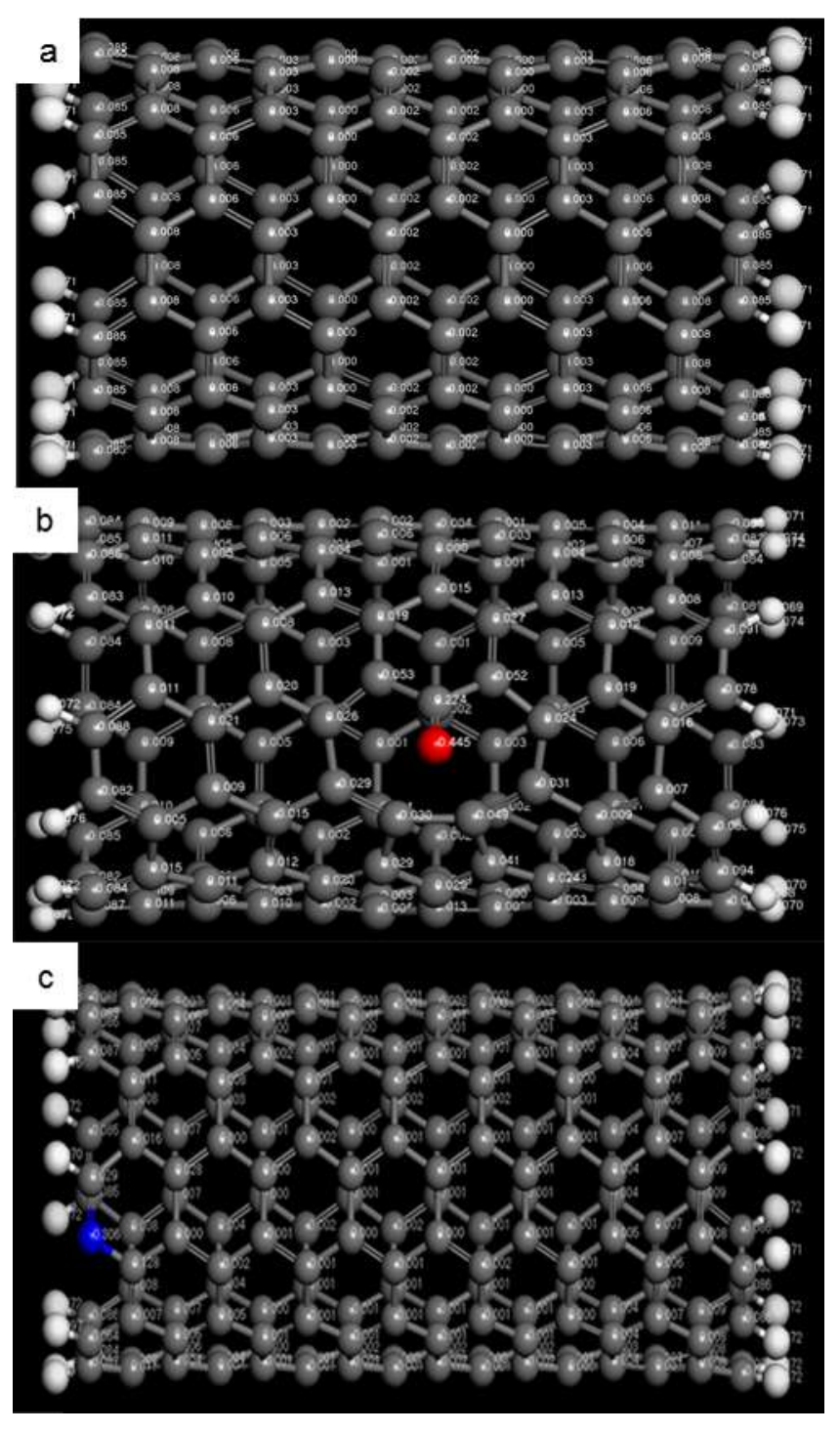

Figure 7. (a) Charge density profile of a pristine SWCNT (b) Charge density profile of a SWCNT modified with $\mathrm{C}=\mathrm{O}$. (c) Charge density profile of a SWCNT doped with pyridinic nitrogen

\section{CONCLUSION}

A facile method for the synthesis of modified multi walled carbon nanotubes is described. RDE testing shows that modifying multi walled carbon nanotubes via thermal treatment under $10 / 90 \mathrm{NH}_{3} / \mathrm{N}_{2}$ gas leads to a highly active ORR catalyst. Elemental analysis was performed via 
XPS and Raman spectroscopy to characterize the active catalyst. Deconvolution of the high resolution C 1s XPS peak showed a presence of carbonyl groups on the surface of the active samples and an absence of this oxygen containing species in the inactive control samples. The higher $\mathrm{D} / \mathrm{G}$ ratio in treated samples vs. untreated samples, evident through Raman spectroscopy and presumably created by the breaking of conjugation at the sites of $\mathrm{C}=\mathrm{O}$ inclusion, further reaffirms the hypothesis that the MWCNTs have indeed been modified with carbonyl groups on their surface. Based on elemental analysis and activity testing, it is clear that the presence of carbonyl groups on MWCNT surfaces is responsible for an improved ORR catalytic efficiency. The mechanism behind this catalytic improvement is explained via STS and molecular modeling. Molecular modeling of pristine CNTs and carbonyl modified CNTs shows that the electron withdrawing effect of the $\mathrm{C}=\mathrm{O}$ group gives rise to multiple, more positive carbon sites in the adjacent carbons compared to the relatively uniform and neutral charge distribution in pristine CNTs. The increase of more positively charged carbons gives rise to more attractive sites for oxygen adsorption, and therefore are responsible for the improved catalytic efficiency. STS studies exhibit experimentally what molecular modelling shows us theoretically. Namely, an increased number of DOS are seen on the surface of M-MWCNTs than are seen on pristine MWCNTs. So, in short, $\mathrm{C}=\mathrm{O}$ groups were introduced into the graphitic surface of MWCNTs via nitrogen replacement following thermal treatment under ammonia gas. These $\mathrm{C}=\mathrm{O}$ groups give rise to new, more positive, carbon sites on the surface when compared to MWCNTs, and therefore more efficient ORR catalysts. The synthesis is a very simple, one step heat treatment process. The simplicity of this method lends itself to facile scalability. The integration of MMWCNTs in PEMFC technology could drastically bring down production costs when compared 
to the standard $\mathrm{Pt} / \mathrm{C}$ catalysts currently used. This could finally make PEMFC automobiles economically viable helping us take a large step towards weening our society off fossil fuels.

\section{EXPERIMENTAL}

\subsection{CATALYST PREPARATION}

Modified carbon nanotubes were prepared via heat treatment under ammonia gas. Approximately $0.075 \mathrm{~g}$ of as-received multi-walled carbon nanotubes purchased from SigmaAldrich ( $>95 \%)$ were placed in an alumina boat (50 mm x $12 \mathrm{~mm}$ x $10 \mathrm{~mm}$ ) which was in turn placed in the center region of an alumina tube (inside diameter $31.75 \mathrm{~mm}$, length $610 \mathrm{~mm}$ ). The tube was placed in an MTI Corporation GSL-1100X tube furnace where it was introduced to a $10 / 90 \mathrm{NH}_{3} / \mathrm{N}_{2}$ atmosphere. The samples were ramped at a rate of $200{ }^{\circ} \mathrm{C} / \mathrm{min}$ to their maximum temperatures which ranged from $200{ }^{\circ} \mathrm{C}$ to $1000{ }^{\circ} \mathrm{C}$ in $100{ }^{\circ} \mathrm{C}$ increments. Once the maximum temperature was reached, the temperature was maintained at the maximum for eight hours prior to cooling naturally to room temperature. Synthesis of the catalysts was carried out at least three times to ensure reproducibility.

Control samples were also prepared using the same procedure mentioned above with the exception of the use of an inert $\mathrm{N}_{2}$ atmosphere rather than the ammonia/nitrogen mix. These samples are denoted with a "C" suffix. For example, the control sample dwelled at $700{ }^{\circ} \mathrm{C}$ is referred to as M-MWCNT_700d_C.

\subsection{CATALYST CHARACTERIZATION}

Various methods were used to determine the characteristics of as prepared catalysts. A Kratos Ultra DLD XPS was used for elemental surface analysis. Topography of the catalysts was observed on a low temperature STM. At the same time, electronic properties were obtained 
including dI/dV vs. V curves indicative of the densities of state (DOS) of the material. Raman spectra were obtained on a Snowy Range Instruments Raman Spectrometer with a green, $532 \mathrm{~nm}$ laser.

\subsection{ELECTRODE PREPERATION}

Working electrodes were prepared by depositing a catalyst/DI water/ethanol/5\% Nafion perfluorinated resin solution onto the glassy carbon disk with a micro-pipette. First, $1 \mathrm{mg}$ of catalyst was measured and placed in a vial. To this, a micro-pipette was used to add $75 \mu \mathrm{L}$ of DI water, $75 \mu \mathrm{L}$ of ethanol and $25 \mu \mathrm{L}$ of $5 \%$ Nafion perfluorinated resin solution (Sigma-Aldrich). This mixture was sonicated for 30 minutes before $3 \mu \mathrm{L}$ of the solution was deposited on the glassy carbon disk via micro-pipette resulting in deposition of $0.04 \mathrm{mg}$ of catalyst on each electrode. The samples were allowed to dry, covered, or in an oven at $50{ }^{\circ} \mathrm{C}$ for 2 hours.

\subsection{ACTIVITY EVALUATION}

All activity tests were performed using an RRDE-3A Rotating Ring Disk Electrode Apparatus manufactured by BAS Inc. All tests were obtained in a $0.1 \mathrm{M} \mathrm{KOH}$ solution with a disk speed of $1600 \mathrm{RPM}$. $\mathrm{Ag} / \mathrm{AgCl}$ reference electrodes, Pt wire counter electrodes and glassy carbon working disk electrodes (area of $7.065 \mathrm{~mm}^{2}$ ) were used. Fifteen linear sweep scans were taken from 1.264 and $-0.536 \mathrm{~V}$ vs. RHE for each sample, and data points were taken from the tenth scan.

\section{ACKNOWLEDGEMENTS}

This research was funded by the National Science Foundation grant for the Dissemination of Nanotechnologies for Energy Production and Environment Protection in Rural Areas of 
Wyoming (NSF-DGE-0948027). Dr. TeYu Chien acknowledges the U.S Department of Energy,

Office of Basic Energy Sciences, Division of Materials Sciences and Engineering for financial support (DEFG02-10ER46728) of this research. Andrew John Yost acknowledges graduate fellowship support from the National Science Foundation and the University of Wyoming EENanotechnology Program (NSF-DGE-0948027). The authors would like to thank Dr. Liang Huang for help with molecular modeling.

\section{REFERENCES}

[1] Gasteiger, H.A. and N.M. Markovic, Just a dream-or future reality? Science, 2009. 324(ANL/MSD/JA-63907).

[2] Stamenkovic, V.R., et al., Improved oxygen reduction activity on Pt3Ni (111) via increased surface site availability. Science, 2007. 315(5811): p. 493-497.

[3] Wagner, F.T., B. Lakshmanan, and M.F. Mathias, Electrochemistry and the future of the automobile. J. Phys. Chem. Lett, 2010. 1(14): p. 2204-2219.

[4] Carpenter, M.K., et al., Solvothermal synthesis of platinum alloy nanoparticles for oxygen reduction electrocatalysis. J Am Chem Soc, 2012. 134(20): p. 8535-8542.

[5] Guo, S., et al., FePt and CoPt nanowires as efficient catalysts for the oxygen reduction reaction. Angewandte Chemie International Edition, 2013. 52(12): p. 3465-3468.

[6] Liang, Y., et al., Covalent hybrid of spinel manganese-cobalt oxide and graphene as advanced oxygen reduction electrocatalysts. J Am Chem Soc, 2012. 134(7): p. 3517-3523.

[7] Liang, Y., et al., Co3O4 nanocrystals on graphene as a synergistic catalyst for oxygen reduction reaction. Nature materials, 2011. 10(10): p. 780-786.

[8] Dumitru, A., M. Mamlouk, and K. Scott, Effect of different chemical modification of carbon nanotubes for the oxygen reduction reaction in alkaline media. Electrochimica Acta, 2014. 135: p. 428-438.

[9] Gasteiger, H.A., et al., Activity benchmarks and requirements for Pt, Pt-alloy, and non-Pt oxygen reduction catalysts for PEMFCs. Applied Catalysis B: Environmental, 2005. 56(1): p. 9-35.

[10] Chen, C.J. and W.F. Smith, Introduction to scanning tunneling microscopy. American Journal of Physics, 1994. 62(6): p. 573-574.

[11] Wilder, J.W., et al., Electronic structure of atomically resolved carbon nanotubes. Nature, 1998. 391(6662): p. 59-62.

[12] Hersam, M.C., Progress towards monodisperse single-walled carbon nanotubes. Nature Nanotechnology, 2008. 3(7): p. 387-394.

[13] Odom, T.W., et al., Atomic structure and electronic properties of single-walled carbon nanotubes. Nature, 1998. 391(6662): p. 62-64.

[14] Odom, T.W., et al., Structure and electronic properties of carbon nanotubes. The Journal of Physical Chemistry B, 2000. 104(13): p. 2794-2809.

[15] Czerw, R., et al., Identification of electron donor states in N-doped carbon nanotubes. Nano Lett, 2001. 1(9): p. 457-460.

[16] Choi, H.J., et al., Defects, quasibound states, and quantum conductance in metallic carbon nanotubes. Physical review letters, 2000. 84(13): p. 2917. 
[17] Terrones, M., et al., Carbon nitride nanocomposites: formation of aligned CxNy nanofibers. Advanced Materials, 1999. 11(8): p. 655-658.

[18] Ajayan, P.M. and J.M. Tour, Materials science: nanotube composites. Nature, 2007. 447(7148): p. 1066-1068.

[19] Horcas, I., et al., WSXM: a software for scanning probe microscopy and a tool for nanotechnology. Review of Scientific Instruments, 2007. 78(1): p. 013705.

[20] Miyamoto, Y., M.L. Cohen, and S.G. Louie, Theoretical investigation of graphitic carbon nitride and possible tubule forms. Solid state communications, 1997. 102(8): p. 605-608.

[21] Yi, J.-Y. and J. Bernholc, Atomic structure and doping of microtubules. Physical Review B, 1993. 47(3): p. 1708.

[22] Terrones, M., et al., Efficient route to large arrays of CNx nanofibers by pyrolysis of ferrocene/melamine mixtures. Applied Physics Letters, 1999. 75(25): p. 3932-3934.

[23] Yang, S., et al., Graphene-Based Carbon Nitride Nanosheets as Efficient Metal-Free Electrocatalysts for Oxygen Reduction Reactions. Angewandte Chemie International Edition, 2011. 50(23): p. 5339-5343.

[24] Wepasnick, K.A., et al., Chemical and structural characterization of carbon nanotube surfaces. Analytical and bioanalytical chemistry, 2010. 396(3): p. 1003-1014.

[25] Colthup, N., Introduction to infrared and Raman spectroscopy. 2012: Elsevier. 


\section{Supporting Information}

\section{A Facile Synthesis of Highly Stable Modified Carbon Nanotubes as Efficient Oxygen Reduction Reaction Catalysts}

John Stacy ${ }^{\mathrm{a}}$, Andrew John Yost ${ }^{\mathrm{c}}$, Yagya N Regmi ${ }^{\mathrm{b}}$, Brian Leonard ${ }^{\mathrm{b}}$, TeYu Chien ${ }^{\mathrm{c}}$, Maohong $\operatorname{Fan}^{\mathrm{a}, \mathrm{d}}$

${ }^{a}$ Department of Chemical and Petroleum Engineering, University of Wyoming, Laramie, Wyoming, 82071, USA

${ }^{b}$ Department of Chemistry, University of Wyoming, Laramie, Wyoming, 82071, USA

${ }^{c}$ Department of Physics and Astronomy, University of Wyoming, Laramie, Wyoming, 82071, USA

${ }^{d}$ School of Energy Resources, University of Wyoming, Laramie, Wyoming, 82071, USA

* Corresponding author: Maohong Fan; mfan@uwyo.edu

Activity 


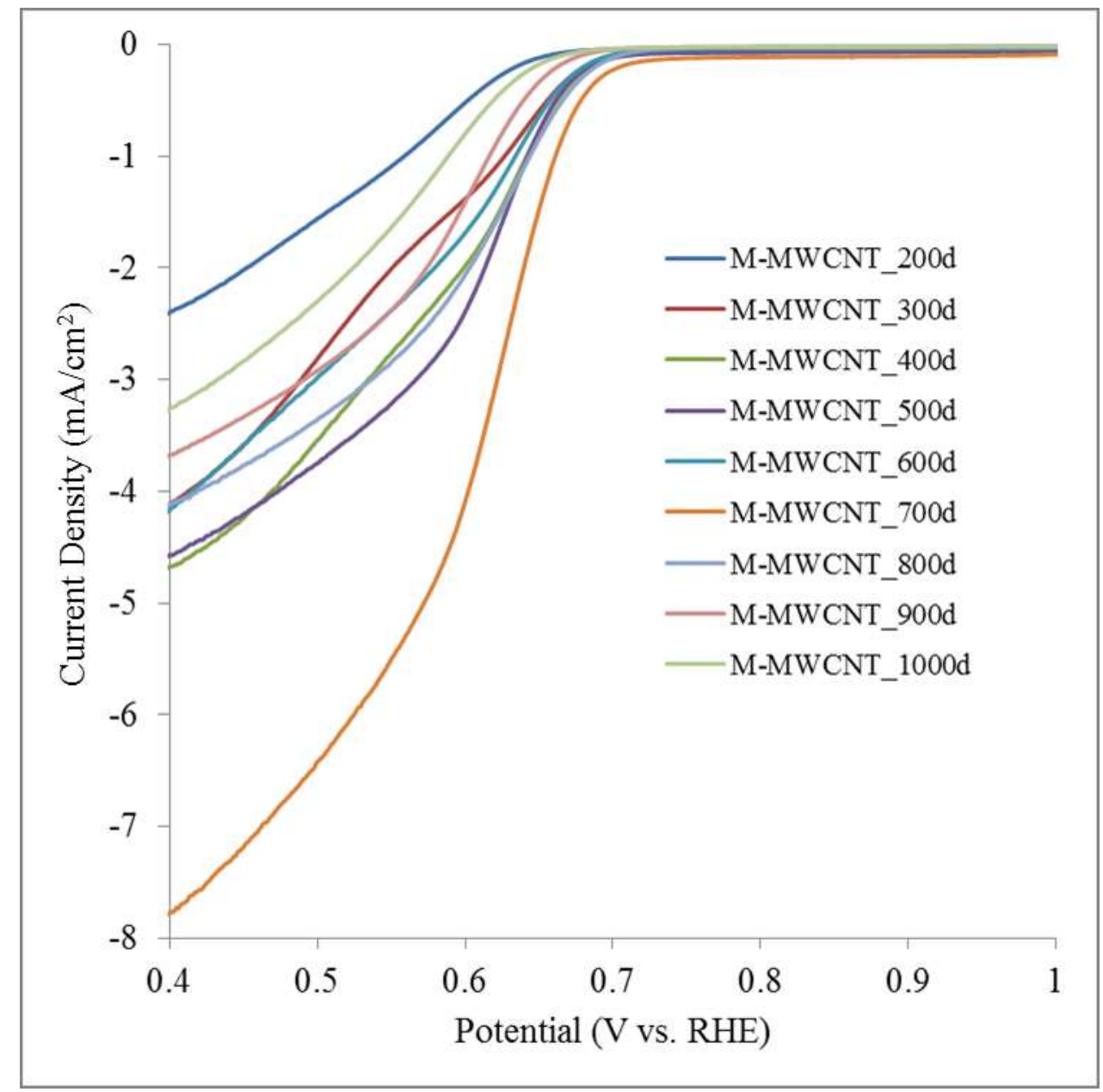

SI Figure 1. LSV's of the dwell samples showing a clear optimization at $700^{\circ} \mathrm{C}$.

\section{$\underline{\text { TAFEL PLOT ANALYSIS }}$}

M-MWCNT_700d displays a Tafel slope near $-60 \mathrm{mV} \mathrm{cm}^{2} \mu \mathrm{A}^{-1}$, indicating that $60 \mathrm{mV}$ need to be applied in order to produce $1 \mu \mathrm{A} \mathrm{cm} \mathrm{cm}^{-2}$. This is compared to the less impressive slope of $-98.78 \mathrm{mV} \mathrm{cm}^{2} \mu \mathrm{A}^{-1}$ displayed by the Pt/MWCNT standard. The Pt/MWCNT standard, however, showed a larger intrinsic electronic interaction between electrolyte and catalyst with an ORR exchange density of $101.33 \mu \mathrm{A} \mathrm{cm} \mathrm{cm}^{-2}$. This was an order of magnitude larger than the exchange density exhibited by M-MWCNT_700d: $14.21 \mu \mathrm{A} \mathrm{cm}^{-2}$. 
SI Table 1. A table showing the Tafel slope and ORR exchange current density of MMWCNT_700d and Pt/MWCNT catalysts.

\begin{tabular}{|c|c|c|}
\hline Catalyst & $\begin{array}{c}\text { Tafel Slope }\left(\mathrm{mV} \mathrm{cm}^{2} \mu \mathrm{A}^{-}\right. \\
1)\end{array}$ & $\begin{array}{c}\text { ORR Exchange Current Density }(\mu \mathrm{A} \\
\left.\mathrm{cm}^{-2}\right)\end{array}$ \\
\hline M-MWCNT_700d & -58.95 & 14.21 \\
\hline Pt/MWCNT & -98.78 & 101.33 \\
\hline & & \\
\hline
\end{tabular}

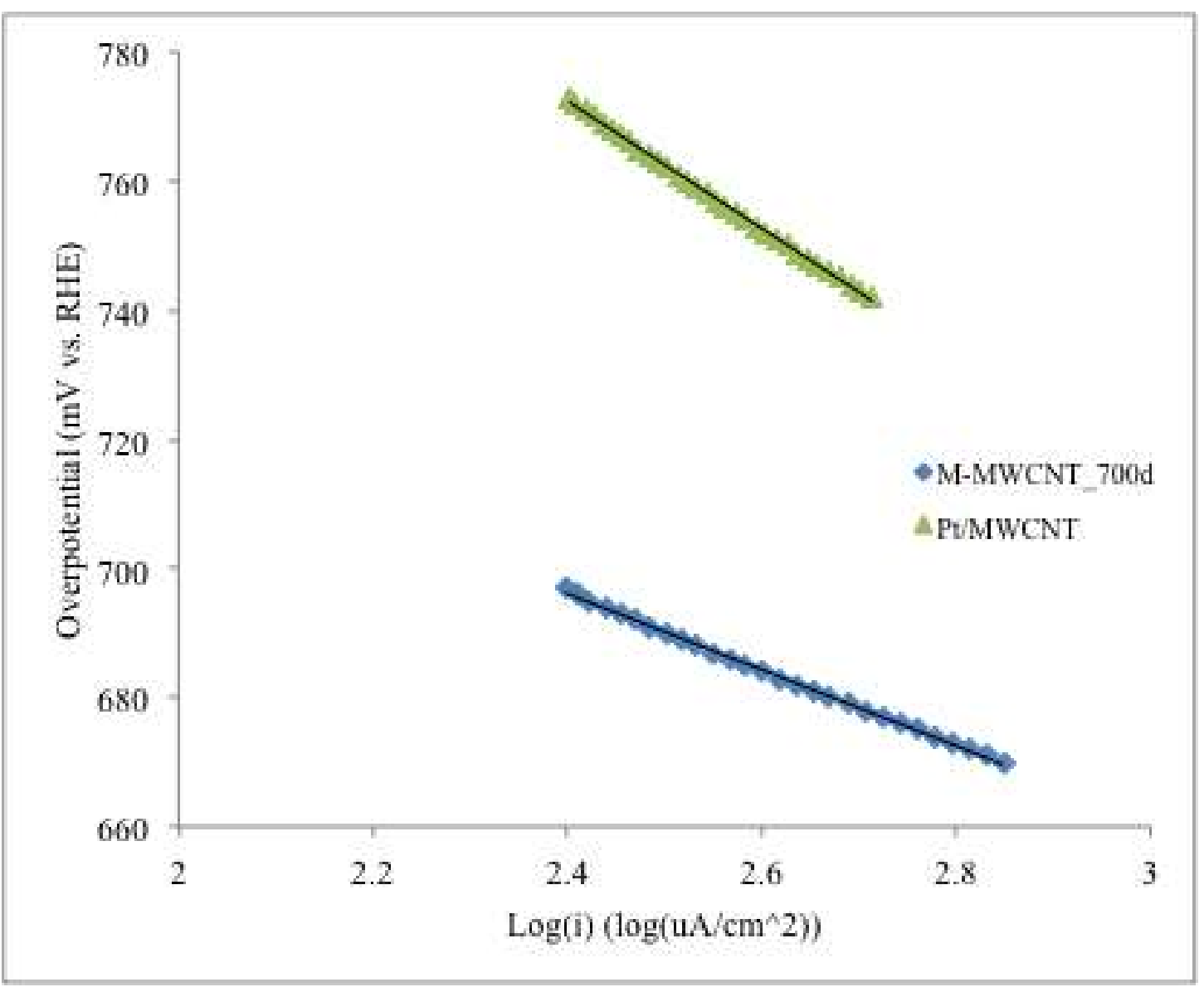


SI Figure 2. Tafel plots of M-MWCNT_700d and Pt/MWCNT

\section{KOUTECKY-LEVICH ANALYSIS}

Koutecky-Levich (K-L) plots are useful tools to determine the ORR pathway utilized by the catalyst. As is mentioned in chapter one, there are two accepted pathways for ORR. The first, called full reduction, follows a four electron path that results in the full reduction of oxygen to water. The second pathway, called partial reduction, involves a two electron pathway and results in the production of hydrogen peroxide. Complete reduction is the preferred pathway since partial reduction results in the production of the less stable and less environmentally friendly product of hydrogen peroxide.

K-L plots are produced by plotting the inverse of the observed current density at a selected voltage ( $0.5 \mathrm{~V}$ vs. RHE), vs. the inverse square root of the rotational speed of the disk. After a linear fit is performed, analysis via the theoretical K-L equation can be carried out.

$$
\frac{1}{J}=\frac{1}{B \omega^{1 / 2}}+\frac{1}{J_{K}}
$$

Equation 1

$$
B=0.62 n F C_{O} D_{O}^{3 / 2} v^{-1 / 6}
$$

Equation 2

Where $\mathrm{J}$ is the measured current density in $\mathrm{mA} \mathrm{cm}^{-2}, \mathrm{n}$ is the number of electrons transferred, $\mathrm{F}$ is the Faraday constant $\left(96,485 \mathrm{C} \mathrm{mol}^{-1}\right), \mathrm{Co}_{\mathrm{o}}$ is the concentration of oxygen in the saturated bulk $\mathrm{KOH}$ solution $\left(1.2 \times 10^{-6} \mathrm{~mol} \mathrm{~cm}^{-3}\right)$, Do is the diffusion coefficient of oxygen in $\mathrm{KOH}\left(1.9 \times 10^{-5}\right.$ $\left.\mathrm{cm}^{2} \mathrm{~s}^{-1}\right) \mathrm{v}$ is the kinematic viscosity of $\mathrm{KOH}\left(0.01 \mathrm{~cm}^{2} \mathrm{~s}^{-1}\right), \omega$ is the rotational speed of the disk 
in radian/sec and $\mathrm{J}_{\mathrm{K}}$ is the kinetic limiting current density which can be determined based on the $y$-intercept of the line of best fit. ${ }^{[1]}$ Using this equation, one can set $1 / \mathrm{B}$ to the slope of the experimentally obtained K-L plot in order to find $\mathrm{n}$, the number of electrons transferred during the process. K-L analysis was carried out for M-MWCNT_700d. The results show that the catalyst utilizes the preferred four electron pathway with $\mathrm{n}$ values $\sim 4$.

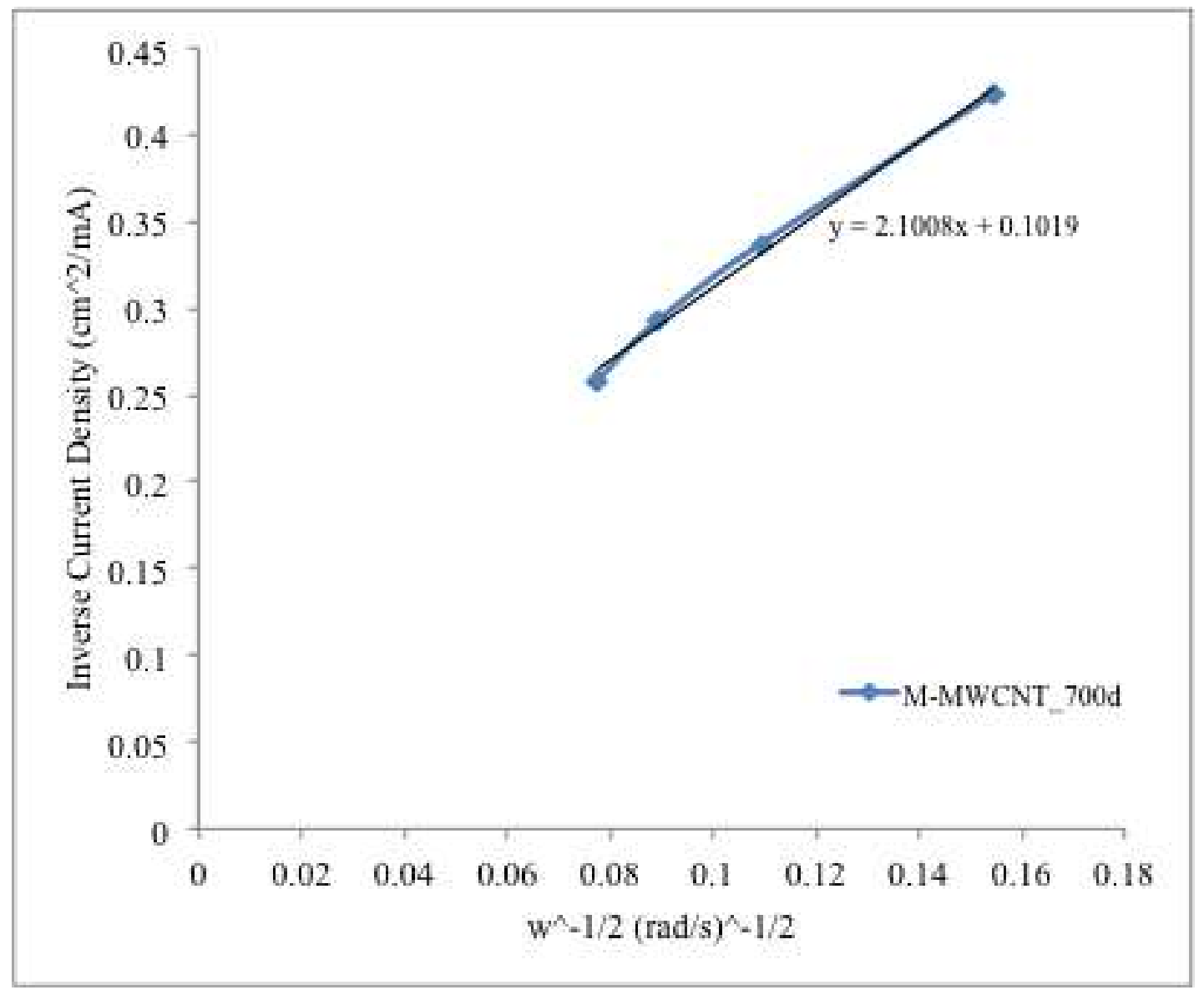

SI Figure 3. K-L plot for M-MWCNT_700d

$\underline{\text { SEM }}$

Initial morphology studies were carried out via SEM. These images served to show that the M-MWCNT's maintained both their nanotube structure and their general size. 


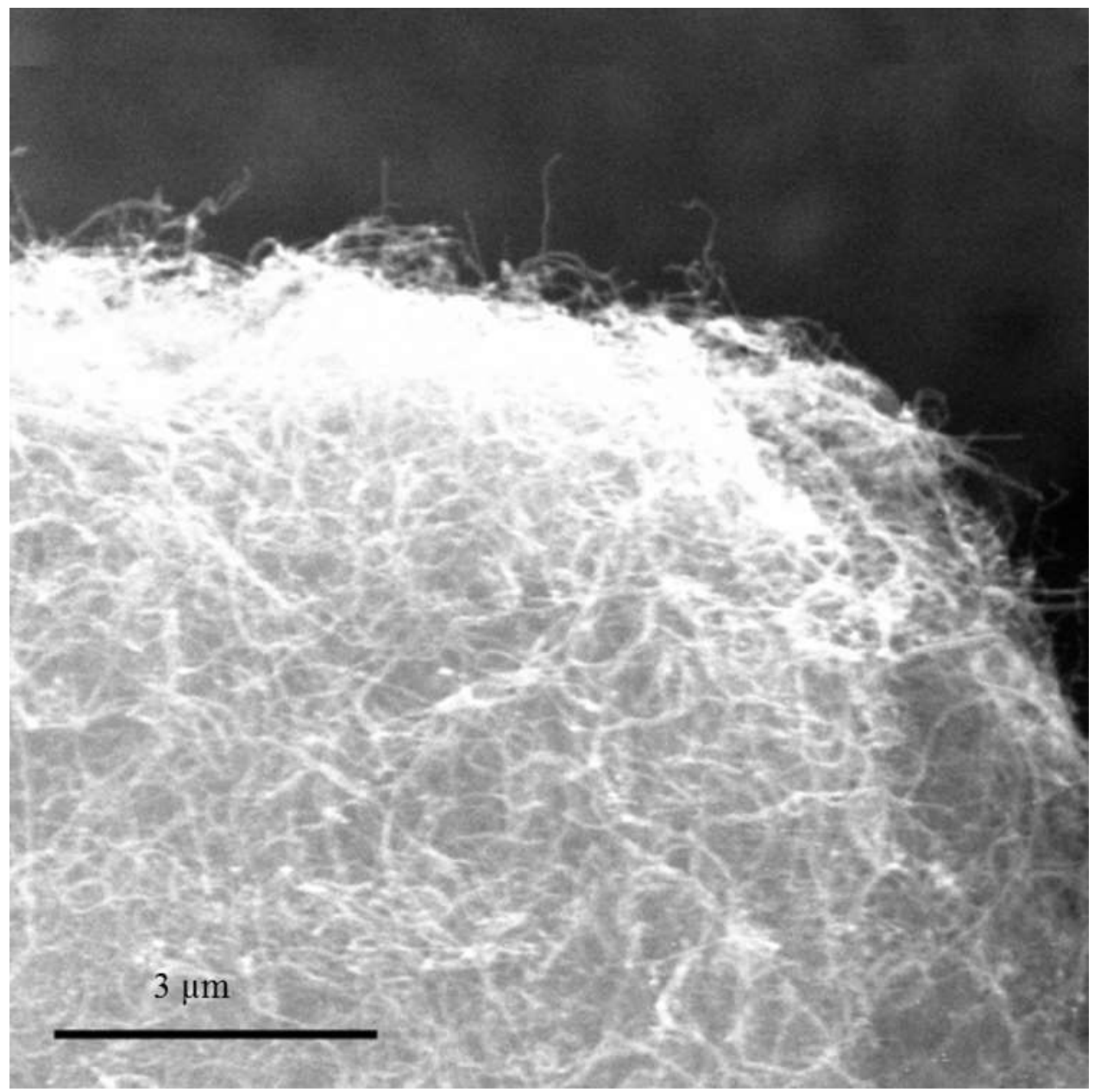

SI Figure 4. SEM image of M-MWCNT-700_d showing nanotube structures with diameters of $<10 \mathrm{~nm}$ 


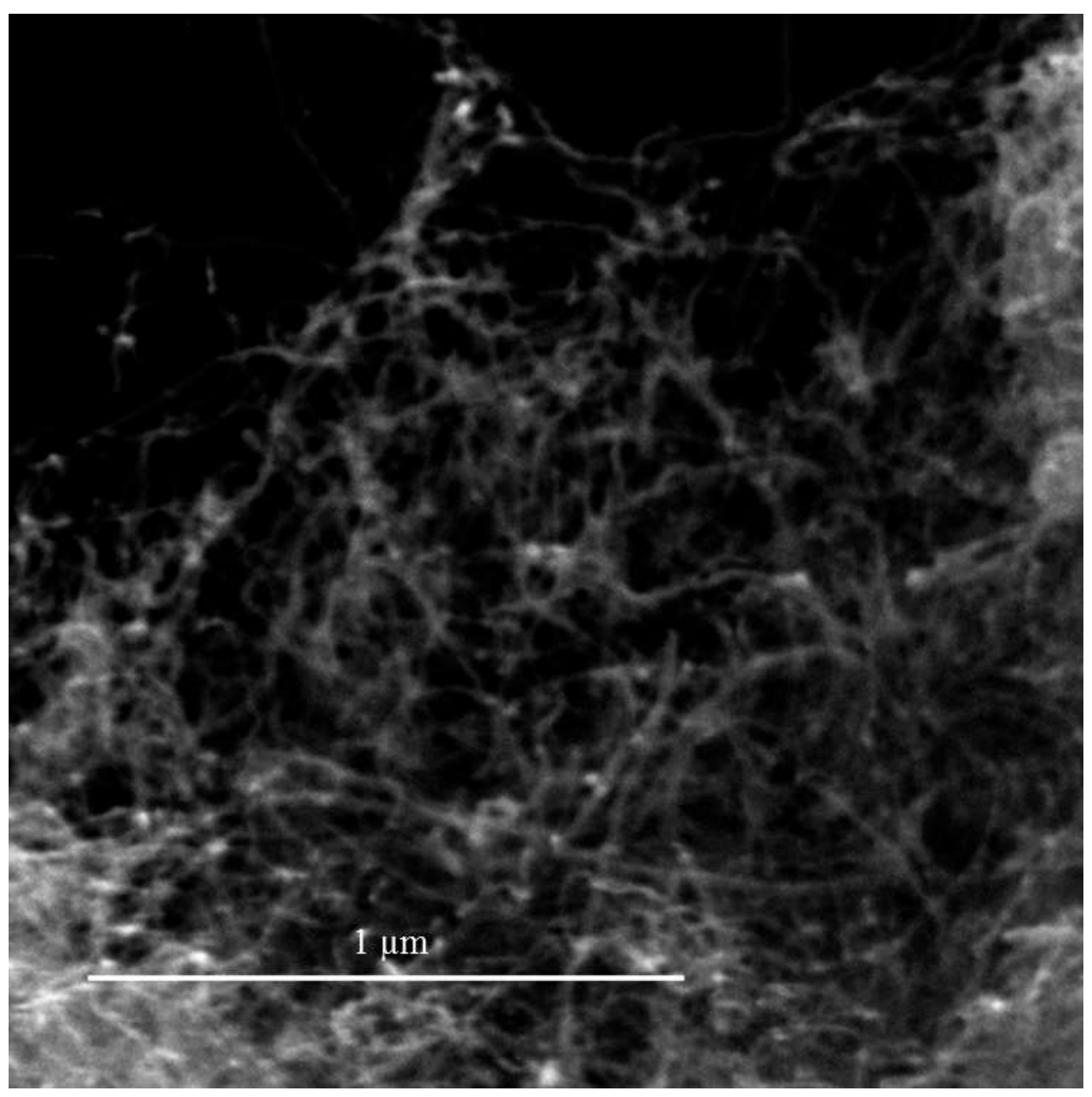

SI Figure 5. SEM image of MWCNT's showing similar structure and size to the treated samples

$\underline{\mathrm{XPS}}$ 


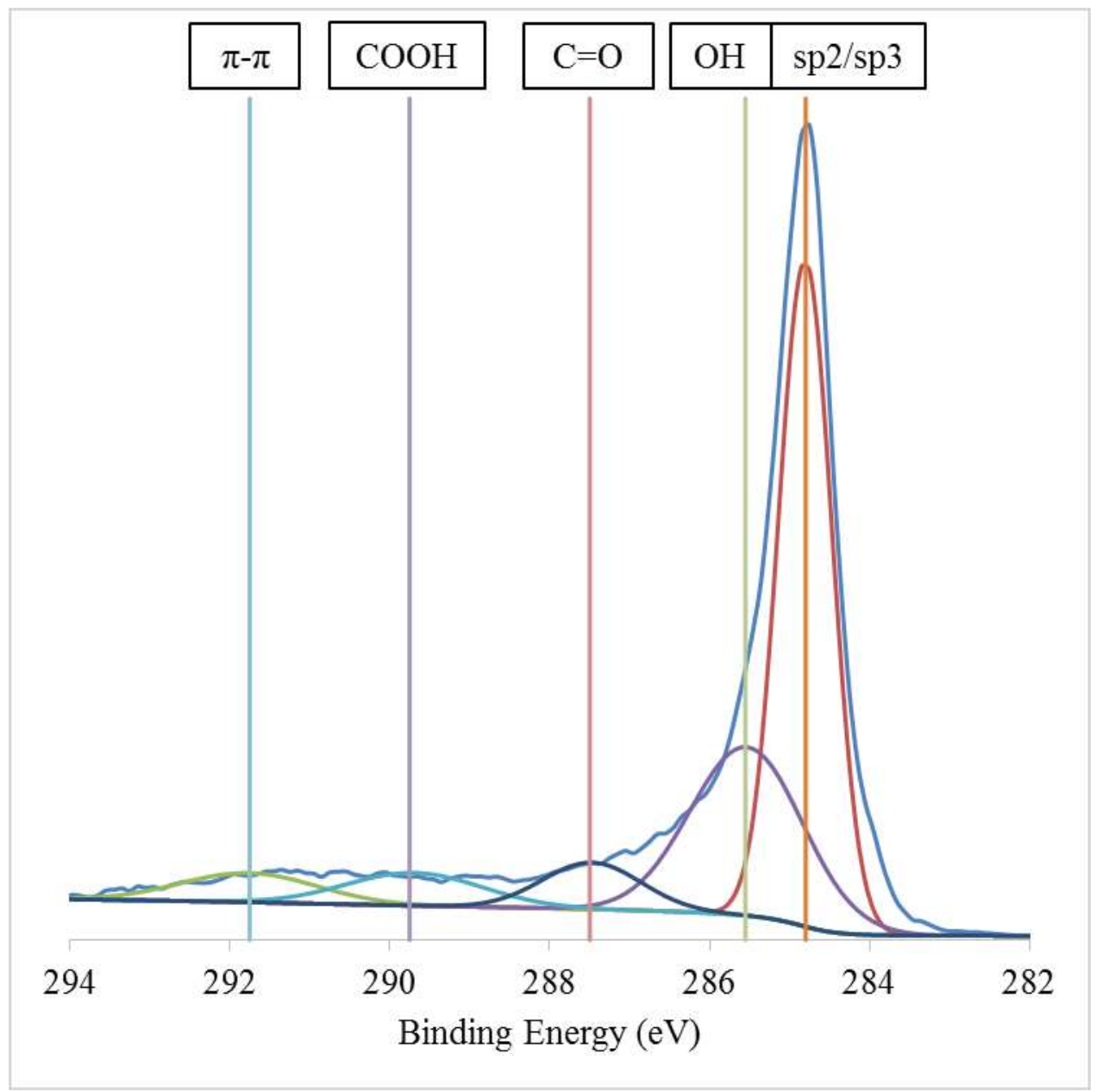

SI Figure 6. High resolution C 1s scan of M-MWCNT_700d 


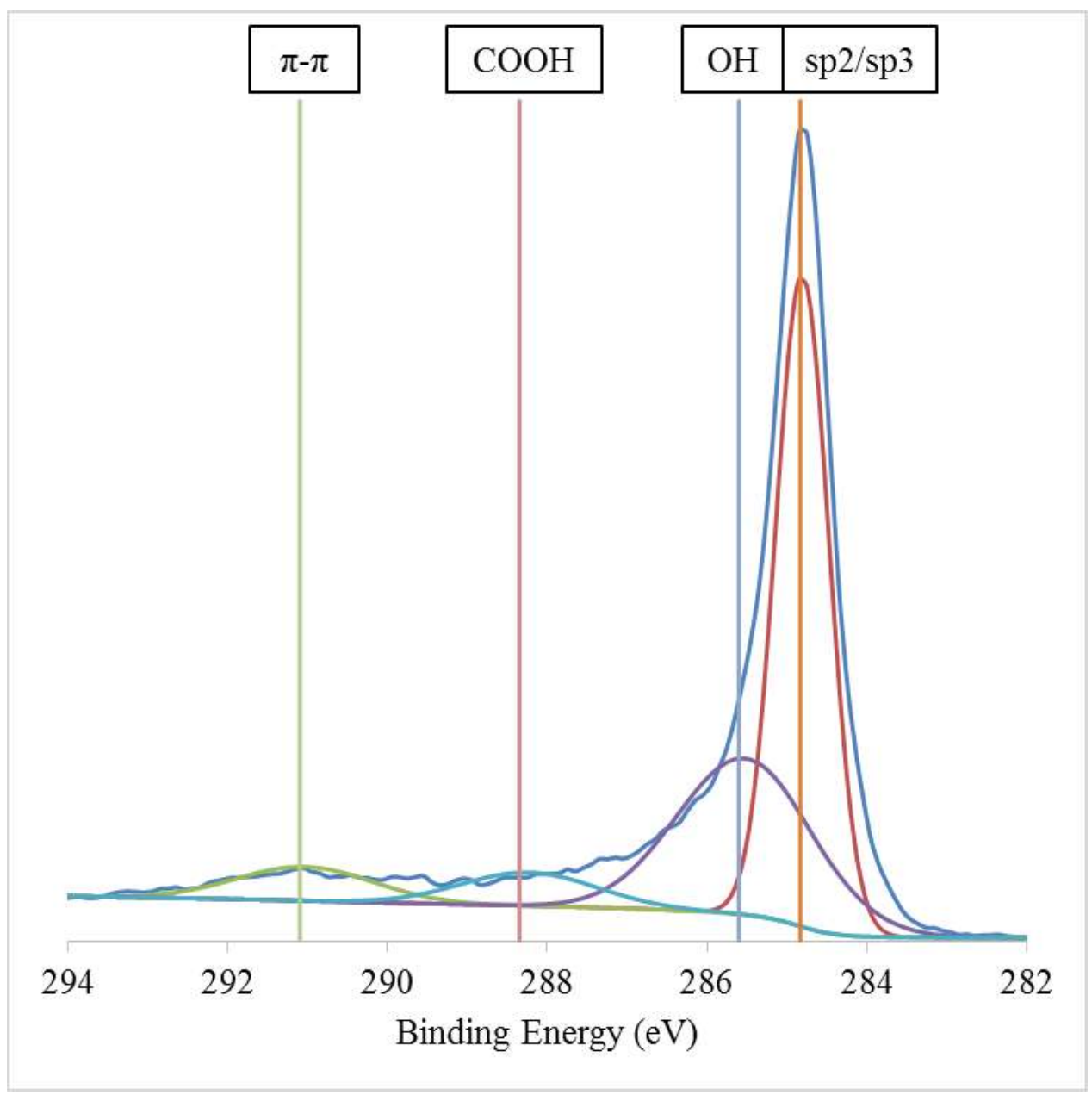

SI Figure 7. High resolution C 1s scan of M-MWCNT_700d_C, control sample heated under nitrogen 


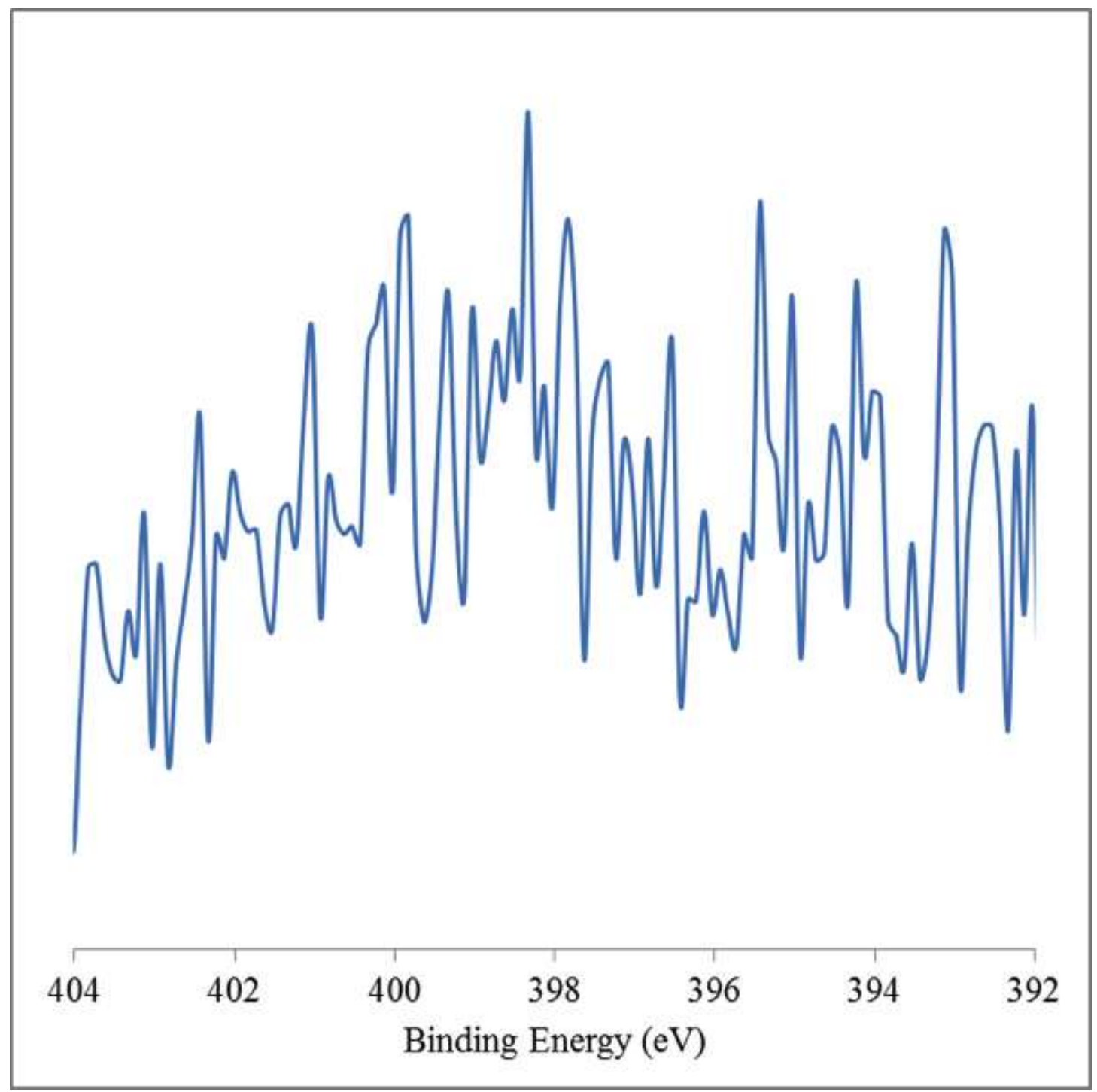

SI Figure 8. HR XPS scan of the N 1s region of M-MWCNT_700d displaying the absence of any $\mathrm{N}$ 1s peak.

XPS data was also gathered for the Pt/MWCNT sample. This data showed a Pt percentage by weight of $6 \%$ on the surface of the catalyst with some residual $\mathrm{K}$ and $\mathrm{Cl}$ from the potassium tetrachloroplatinate precursor. 


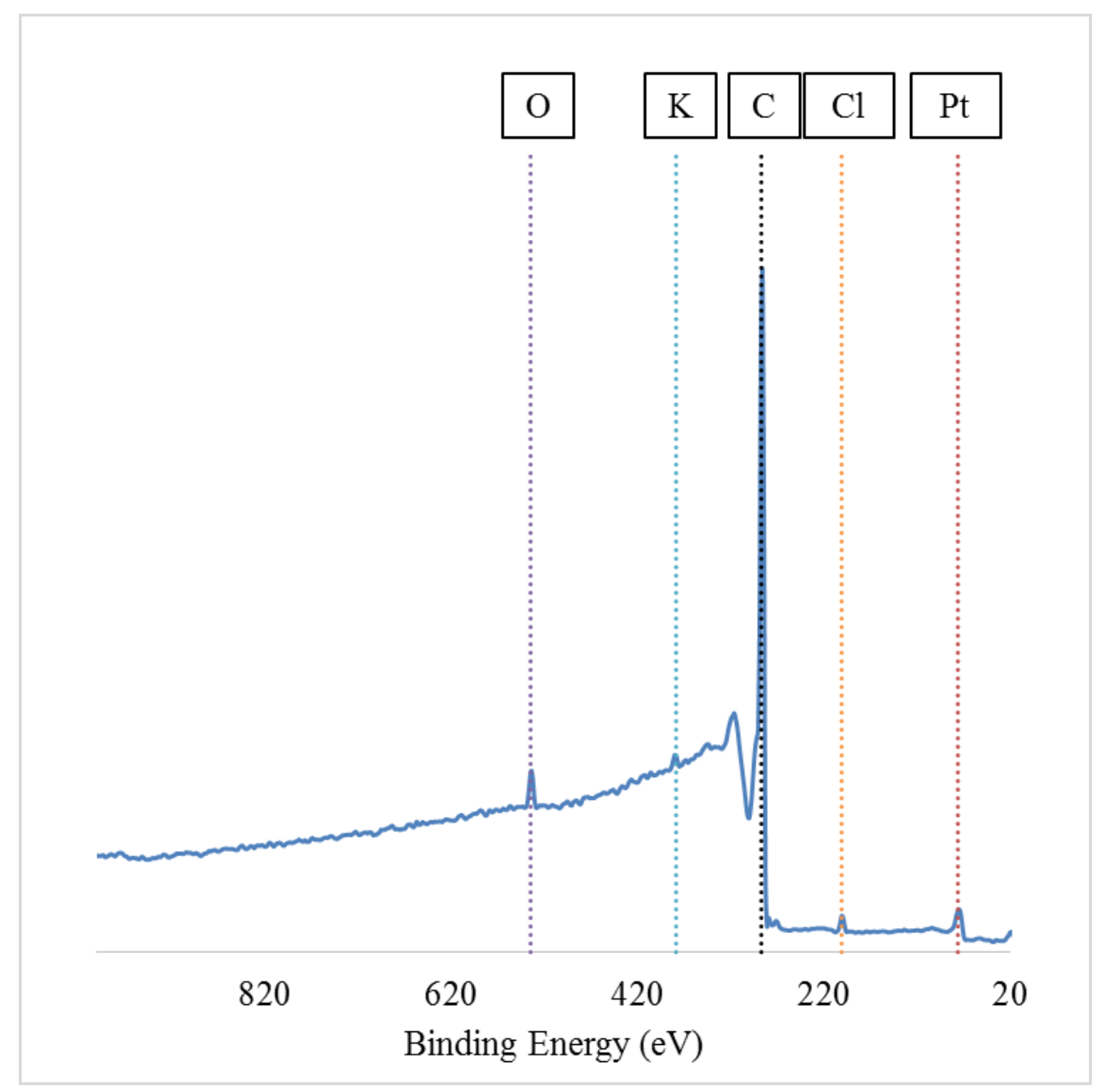

SI Figure 8. XPS survey scan for the Pt/MWCNT standard which shows a surface percentage of $6 \% \mathrm{Pt}$.

$\underline{\text { FTIR }}$

FTIR experiments were performed on a Nicolet iS50 FT-IR. Experiments were carried out on M-MWCNT_700d as well as untreated MWCNTs for comparison sake. Peaks present in both samples include those at $1030 \mathrm{~cm}^{-1}$, indicative of OH groups, $1940-1950 \mathrm{~cm}^{-1}$, indicative of non-conjugated $\mathrm{C}=\mathrm{O}$ groups, $2150 \mathrm{~cm}^{-1}$, indicative of aromatic carbons, $2850 \mathrm{~cm}^{-1}$, indicative of terminal $\mathrm{CH}_{2}$ and $2960 \mathrm{~cm}^{-1}$ indicative of terminal $\mathrm{CH} .{ }^{[2]}$ The most striking observation made comparing M-MWCNTs and untreated MWCNTs is the presence of the peak at $1600 \mathrm{~cm}^{-1}$ in M- 
MWCNT_700d and the absence of this peak in the untreated MWCNT sample. This peak is indicative of conjugated $\mathrm{C}=\mathrm{O}$ species within the graphitic plane of the MWCNT surface. This is commensurate with the results obtained via the high resolution C 1s XPS scan which shows a presence of carbonyl species in the active samples and the absence of these species in the less active control samples. This further supports the idea that the $\mathrm{C}=\mathrm{O}$ inclusion on the MWCNT surface encourages high ORR efficiency.

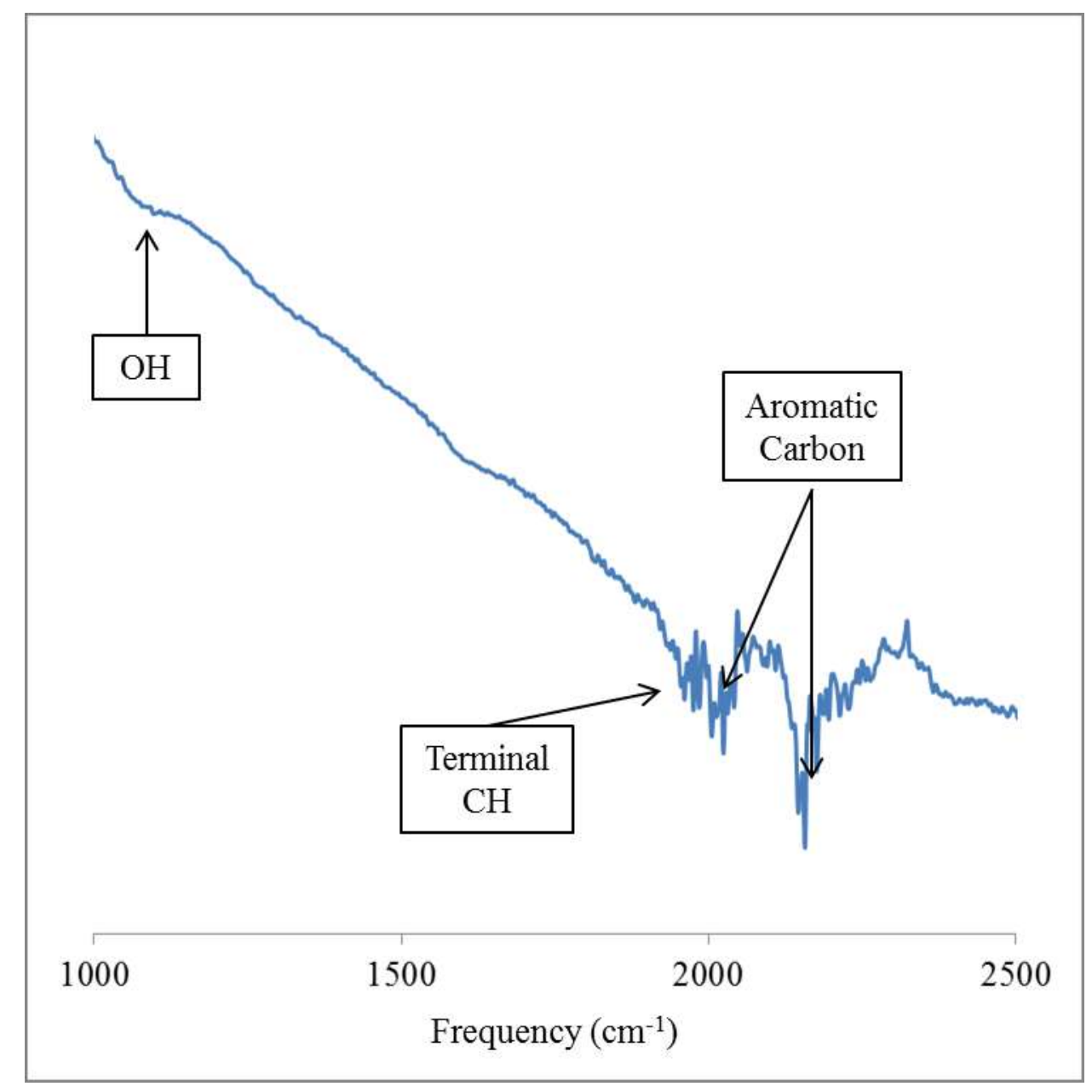

SI Figure 9. FTIR of untreated MWCNTs 


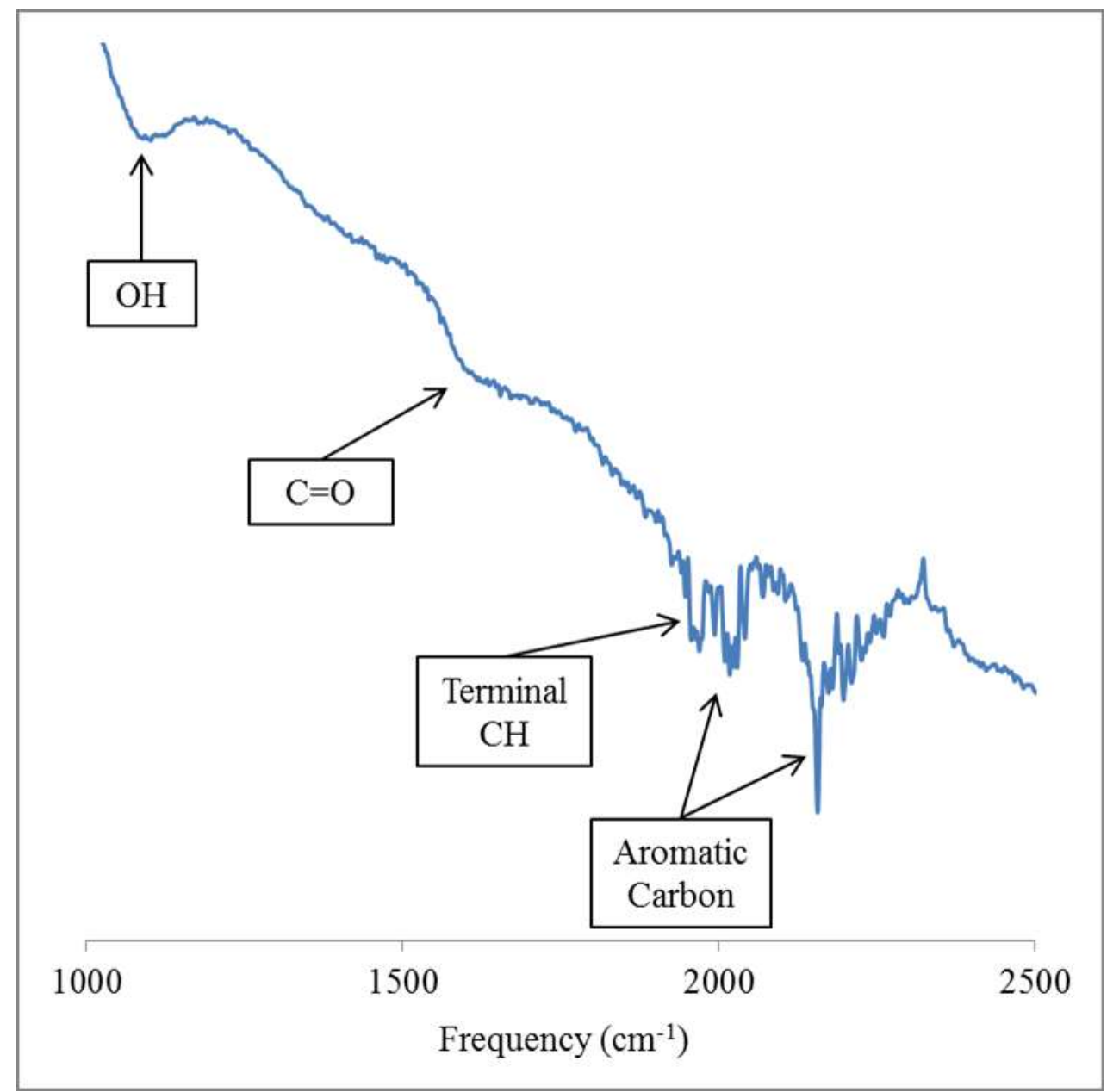

SI Figure 10. FTIR of M-MWCNT_700d 


\section{Z-height and width profiles of STM images}

Figures 15-18 show STM images from the main manuscript corresponding to Figure 4b-e in the main text. Below each Figure are line profiles, extracted using WsXM, ${ }^{[3]}$ corresponding to the lines in the STM z-topography image. As you can see in Figure 15, line profiles indicate individual nanotubes within the untreated nanotube bundle range from $\approx 1.9-4.2 \mathrm{~nm}$ and the diameter of the bundle itself is $\approx 20 \mathrm{~nm}$. Figure 16 shows an isolated untreated nanotube near a nanotube bundle. The isolated nanotube is $\approx 3.2 \mathrm{~nm}$ in diameter according to the line profile. Figure 17 shows an STM image of an M-MWCNT_700d bundle with a diameter of $\approx 7.0 \mathrm{~nm}$, and it can be seen from the line profiles that the individual nanotubes have diameters ranging from $\approx 0.6-2.0 \mathrm{~nm}$. Figure 18 is an STM image of an isolated treated MWCNT with diameter of $\approx 2.0 \mathrm{~nm}$. The line profiles, 1 and 2 , indicate that the hexagonal hole spacing along the edge is $\approx 1.7 \mathrm{~nm}$ apart. More analysis on a zoomed image with lattice overlay is necessary to determine the lattice constant. 

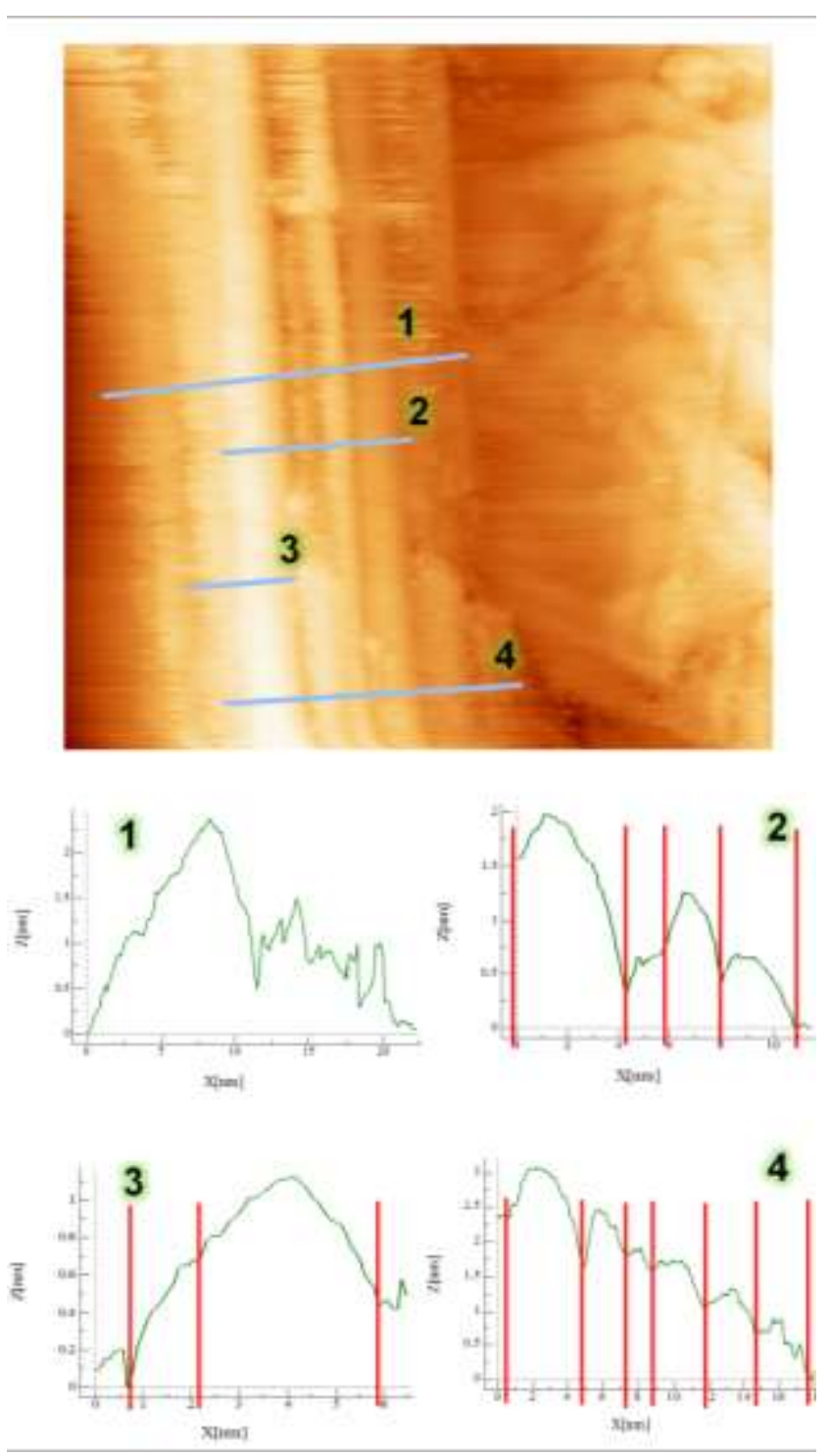

SI Figure 11. STM image of an untreated MWCNT bundle with line profiles 


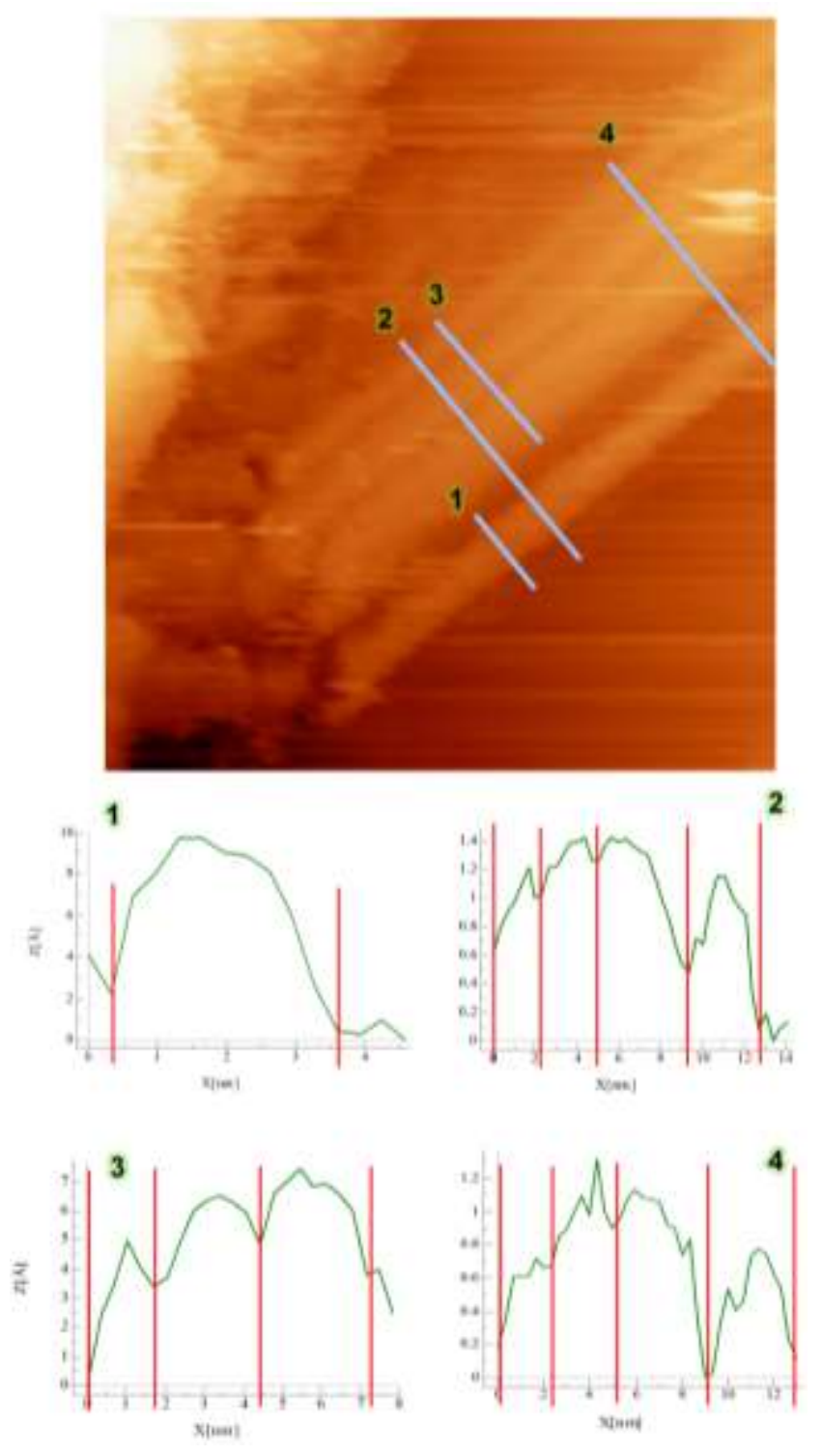

SI Figure 12. STM image of an isolated untreated MWCNT near a nanotube bundle with line profiles 

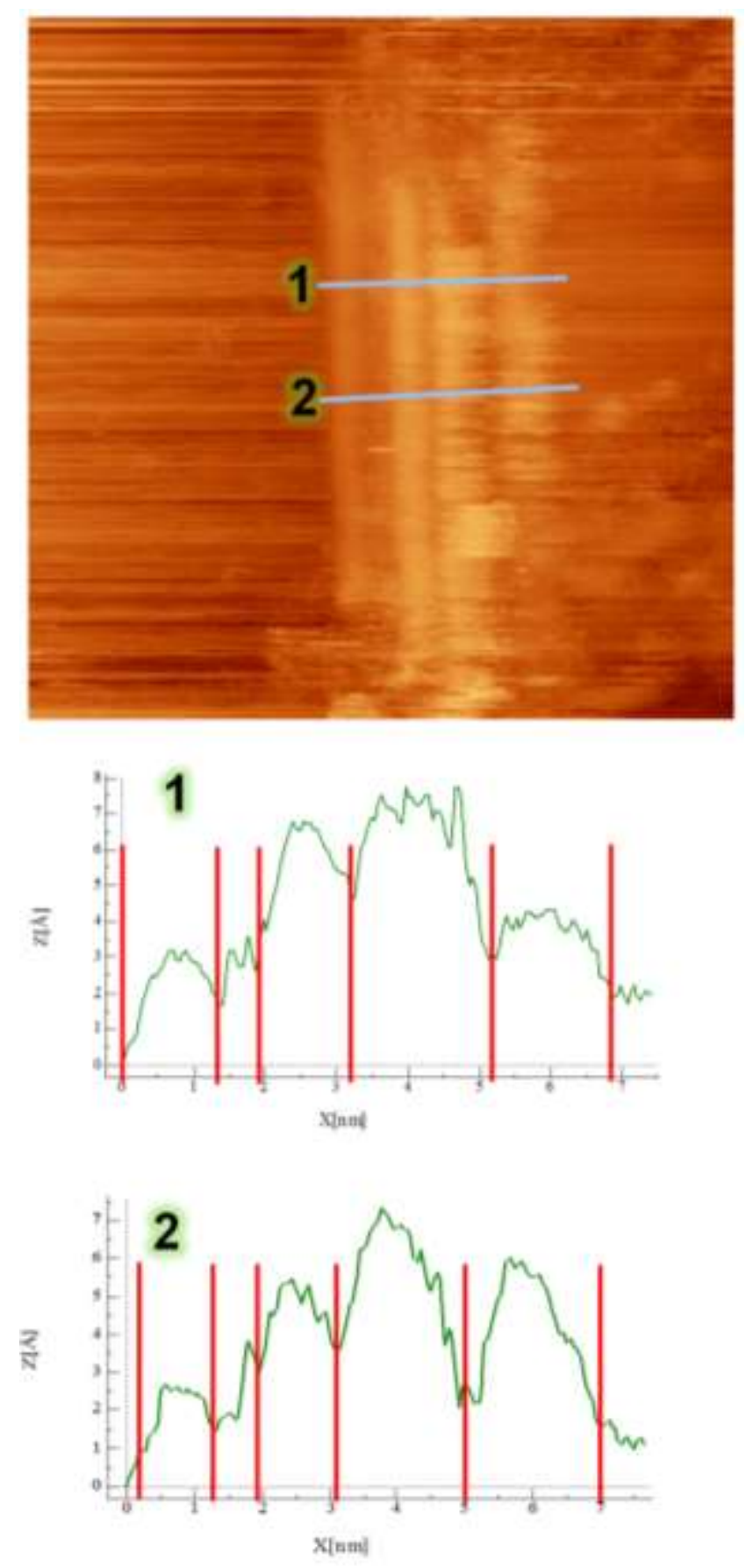

SI Figure 13. STM image of an M-MWCNT_700d bundle with line profiles 


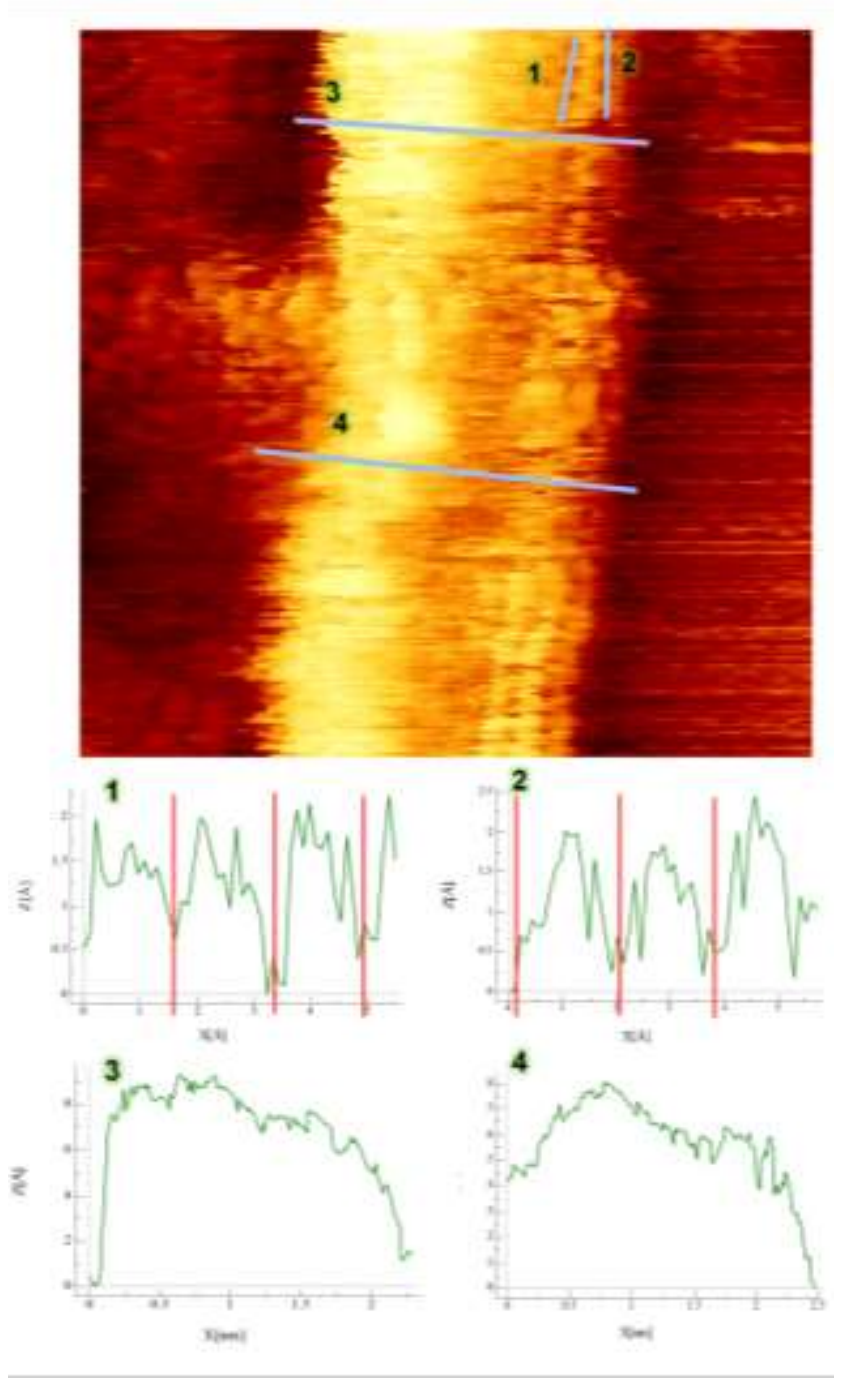

SI Figure 14. STM image of an isolated M-MWCNT_700d with line profiles 


\section{Dropcast solution concentration characterization with AFM}

$0.5 \mathrm{mg}$ of untreated or treated MWCNT powder were mixed into $1 \mathrm{~mL}$ of 2-propanol and then sonicated in an icebath for approximately $5 \mathrm{~min}$. This solution was then dropcast onto and $\mathrm{Si}(100)$ substrate. Atomic force microscopy was used to inspect the distribution of isolated nanotube bundles, as is seen in Figure 20 a-d. Figure 20(a) shows that even at the $0.5 \mathrm{mg} / \mathrm{mL}$ concentration large $\mu \mathrm{m}$ nanotube clusters are present. Figure 23b-d also show that parts of the substrate surface contain isolated nanotube bundles similar in size to what is seen in STM images. This was a necessary characterization as the surface roughness can dictate whether or not atomic resolution can be achieved. $1 \mathrm{mg} / \mathrm{mL}$ and $0.25 \mathrm{mg} / \mathrm{mL}$ solutions were also measured with AFM, but the data is not shown. The $1 \mathrm{mg} / \mathrm{mL}$ solution resulted in continuous cluster coverage with no isolated nanotube bundles and high roughness meaning it would be too difficult 
to scan in STM. Also the $0.25 \mathrm{mg} / \mathrm{mL}$ resulted in isolated nanotube bundles separated by more than $10 \mu \mathrm{m}$ meaning it would take too much time to find in STM on the nanoscale. 

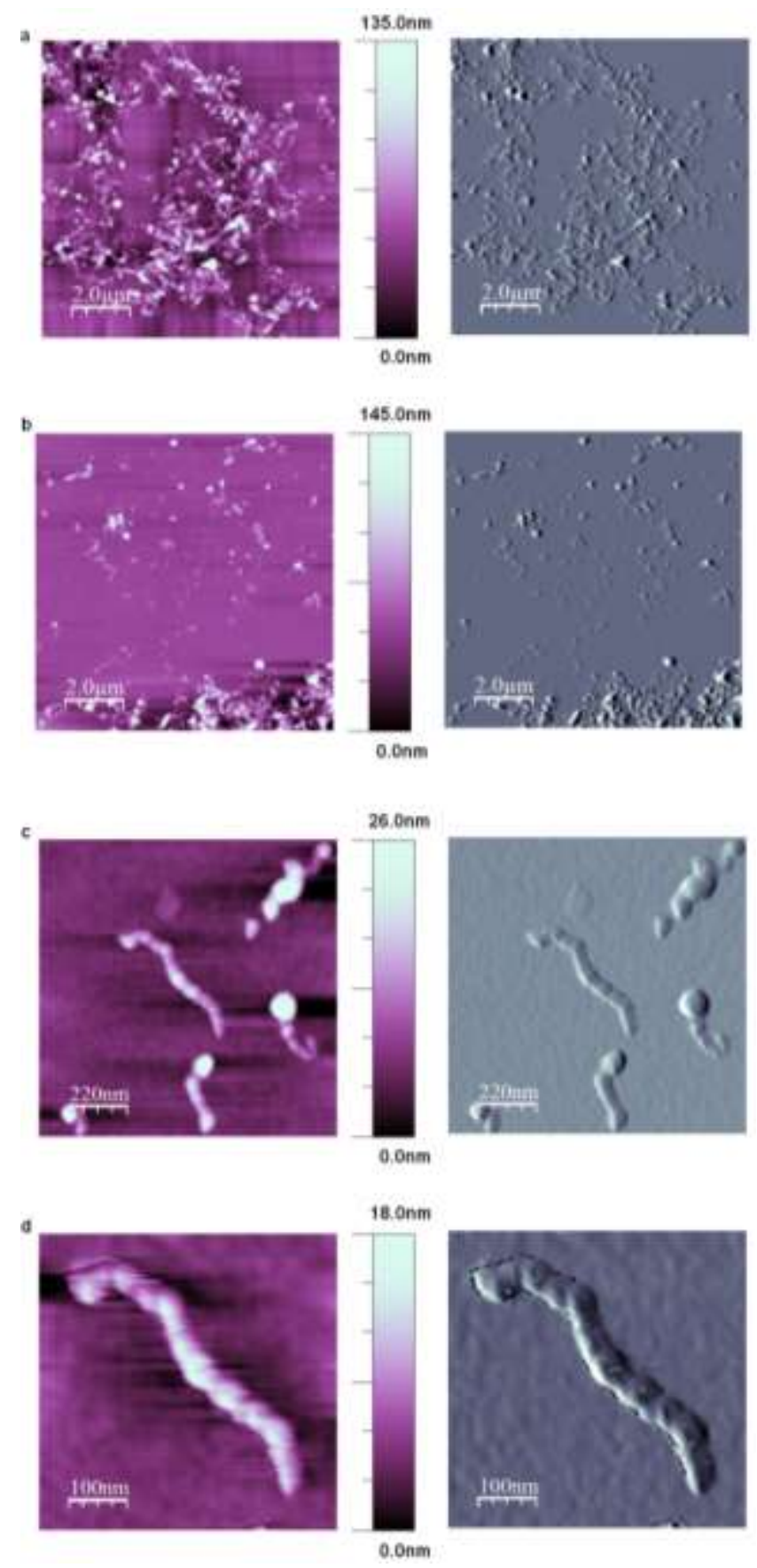

SI Figure 16. (a-d) AFM images of untreated MWCNTs deposited at a concentration of 0.5 $\mathrm{mg} / \mathrm{mL}$ 


\section{REFERENCES}

[1] Wepasnick, K.A., et al., Chemical and structural characterization of carbon nanotube surfaces. Analytical and bioanalytical chemistry, 2010. 396(3): p. 1003-1014.

[2] Colthup, N., Introduction to infrared and Raman spectroscopy. 2012: Elsevier.

[3] Horcas, I., et al., WSXM: a software for scanning probe microscopy and a tool for nanotechnology. Review of Scientific Instruments, 2007. 78(1): p. 013705.

[4] Bernhardt, T., B. Kaiser, and K. Rademann, Formation of superperiodic patterns on highly oriented pyrolytic graphite by manipulation of nanosized graphite sheets with the STM tip. Surface science, 1998. 408(1): p. 86-94.

[5] Wilder, J.W., et al., Electronic structure of atomically resolved carbon nanotubes. Nature, 1998. 391(6662): p. 59-62.

[6] Hersam, M.C., Progress towards monodisperse single-walled carbon nanotubes. Nature Nanotechnology, 2008. 3(7): p. 387-394.

[7] Odom, T.W., et al., Atomic structure and electronic properties of single-walled carbon nanotubes. Nature, 1998. 391(6662): p. 62-64.

[8] Odom, T.W., et al., Structure and electronic properties of carbon nanotubes. The Journal of Physical Chemistry B, 2000. 104(13): p. 2794-2809. 
